\title{
Molecular Orbital Insights of Transition Metal-Stabilized Carbocations
}

\author{
Hannah Goodman ${ }^{\dagger}$, Liangyong $\mathrm{Mei}^{\dagger}$ and Thomas L. Gianetti* \\ Department of Chemistry and Biochemistry, University of Arizona, Tucson, AZ, United States
}

Transition metal-stabilized carbocations are characterized by synthetically valuable interactions, yet, to date there are no comprehensive reports of the many bonding modes that can exist between a metal and carbocation. This review summarizes developments in these complexes to provide a clear picture of their properties and reactivities. In order to strategically exploit them, we propose this summary of the different bonding modes for transition metal-carbocation complexes. These models will help chemists understand the orbital interactions involved in these compounds so that they can approach their synthetic goals most effectively. Multiple transition metals and carbocations will be discussed.

OPEN ACCESS

Edited by:

Luís D. Carlos,

University of Aveiro, Portugal

Reviewed by:

Domenica Scarano,

University of Turin, Italy

Ahmed A. Al-Amiery,

National University of Malaysia,

Malaysia

*Correspondence:

Thomas L. Gianetti

tgianetti@email.arizona.edu

tThese authors have contributed equally to this work

Specialty section:

This article was submitted to Inorganic Chemistry,

a section of the journal

Frontiers in Chemistry

Received: 21 February 2019

Accepted: 02 May 2019

Published: 04 June 2019

Citation:

Goodman H, Mei L and Gianetti TL (2019) Molecular Orbital Insights of Transition Metal-Stabilized

Carbocations. Front. Chem. 7:365.

doi: 10.3389/fchem.2019.00365
Keywords: metal complexes, carbocation, bonding model, metal-carbocation interaction, molecular orbital interactions

\section{INTRODUCTION}

The structures, properties, and reactivities of organometallic complexes depend mostly on their ligand environment. Ligands are used to improve catalyst efficiency and accelerate the discovery of new reactivity modes. We will use M. Green's seminal model for Covalent Bond Classification (CBC method) (Green, 1995; Parkin, 2007) to define 2-center metal-ligand interactions of organometallic compounds as $\mathrm{ML}_{1} \mathrm{X}_{\mathrm{X}} \mathrm{Z}_{\mathrm{Z}}$, where the ligand atoms are classified as $\mathrm{L}, \mathrm{X}$, and $\mathrm{Z}$ ligands (Figure $\mathbf{1 A}$ ). L-type ligands are Lewis bases that donate two electrons to form a dative $\mathrm{L} \rightarrow \mathrm{M}$ bond (e.g., $\mathrm{PR}_{3}$, $\mathrm{NR}_{3}$, OR). X-type ligands donate one electron, requiring oxidation of the metal center to form classical covalent $\mathrm{M}-\mathrm{X}$ bonds (e.g., $\mathrm{H}^{-}, \mathrm{RO}^{-}, \mathrm{Cl}^{-}$). Z-type ligands are Lewis acids that accept a pair of electrons from the metal to form a dative $\mathrm{M} \leftarrow \mathrm{Z}$ bond (e.g., $\mathrm{SO}_{2}, \mathrm{BR}_{3}$ ). Since transition metals (TMs) are typically defined as electron-deficient species, the majority of ligands that have been developed are electron-rich Lewis-basic moieties (L- and X-types) that aim to complete the valence shell of the transition metal (also known as the 18 electron rule). However, transition metals also exhibit Lewis-basic character from metal-to-ligand back-donation from partial filling of their upper valence $d$ shell. Organometallic chemists have recognized how this basicity can be used to promote interactions between a TM and a Lewis acid moiety, where the acid acts as a $\sigma$-acceptor (L-type) and not a $\sigma$-donor (Z-type) ligand.

The first example of Lewis acid-metal coordination was reported in 1970 (Shriver, 1970), yet the incidence of $\mathrm{M} \leftarrow \mathrm{Z}$ complexes remained scarce for several decades. The scope of Lewis acids acting as $\sigma$-acceptor ligands has been significantly extended over the last two decades with the development of ambiphilic ligands-ligands that contain both electron donor (L-type) and acceptor (Z-type) groups (Amgoune and Bourissou, 2011; Braunschweig and Dewhurst, 2011; Owen, 2012, 2016; Bouhadir and Bourissou, 2016; Jones and Gabbaï, 2016). Transition metals exhibit similar ambiphilic character since they contain both filled and empty d-orbitals. When ambiphilic ligands are used, the metal center coordinates to the L-type moiety of the ligand and the degree of coordination to the Lewis acid moiety is increased (Figure 1B). The Z-type ligand can stabilize a 

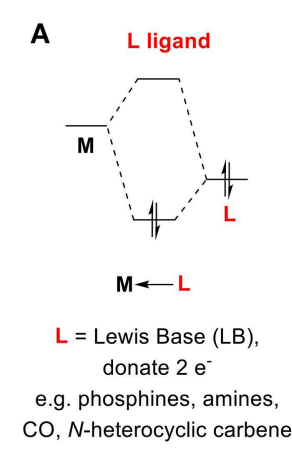

$\mathrm{CO}, \mathrm{N}$-heterocyclic carbene
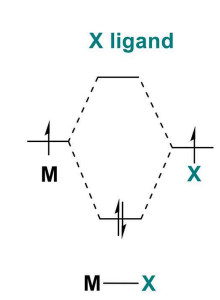

$\mathrm{X}=$ Radical

donate $1 \mathrm{e}^{-}$

e.g. $\mathrm{H}$, halogen, alkyl,

aryl, alkoxyl ...

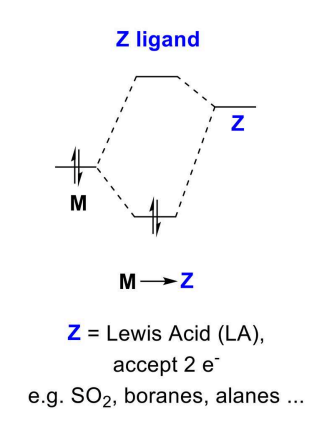

B
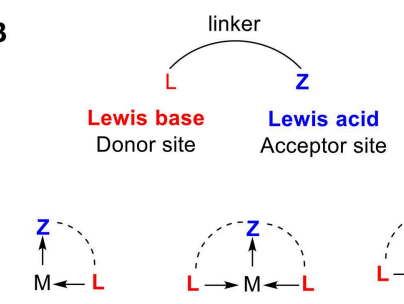

Bidentate

$\kappa^{2}$ - Ligand

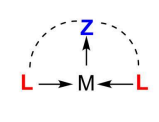

Tridentate

$\kappa^{3}$ - Ligand

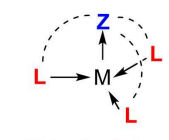

Tetradentate

$\kappa^{4}$ - Ligand

...

FIGURE 1 | (A) Simplified orbital diagrams associated with $M-L, M-X$, and $M-Z$ interaction. (B) Schematic representation of ambiphilic ligands.

vacant orbital of the transition metal center while drawing electron density from the filled d-orbitals because of its $\sigma$ accepting properties. This interaction determines the electronic properties and reactivities of the metal (You et al., 2018). The synthesis, coordination chemistry, and reactivity of ambiphilic ligands and their metal complexes have been extensively studied and well-summarized in several recent reviews (Amgoune and Bourissou, 2011; Braunschweig and Dewhurst, 2011; Owen, 2012, 2016; Bouhadir and Bourissou, 2016; Jones and Gabbaï, 2016). Surprisingly, none of these reports have mentioned carbocations as Lewis acid Z-type ligands, and they neglect to examine the interactions between transition metals and persistent carbocations.

In organic chemistry, carbocations are ubiquitous. The field of carbocation chemistry has rapidly developed since its conception in 1901 when Norris discovered the first stable carbocations, triphenylmethyl ions $\left(\mathrm{PH}_{3} \mathrm{C}^{+}\right)$(Norris, 1901; Norris and Sanders, 1901) Carbocations have been identified as key intermediates in many organic reactions, including electrophilic aromatic substitutions, unimolecular nucleophilic substitutions, addition-eliminations, and many rearrangements (Olah, 2004). The significance of carbocations as reactive intermediates in acid-mediated reactions was also highlighted when Professor Olah was awarded the Nobel Prize in Chemistry to in 1994 for his contributions to carbocation chemistry (Olah, 1995). The diverse applications of carbocations in organic chemistry is outside of the scope of this review, but interested readers are encouraged to consult the many reviews published on their synthesis and applications.

This review focuses on organometallic complexes that contain a carbocation (Z-type ligand), within their first coordination sphere. In 1972, Olah proposed carbenium and carbonium ions as two distinct types of carbocations that are differentiated by their structures (Olah, 1972). The "classical" trivalent carbenium ion contains an $s p^{2}$-hybridized electron-deficient carbon atom (Figure 2A), while the "non-classical" carbonium ion is defined as a penta- (or higher) coordinate carbon that involves a 3-center2-electron bond (Figure 2B; Winstein and Trifan, 1952; Olah, 1972). This review focuses on classical carbenium ions, which we will refer to as carbocations.
Carbocations can be transient, extremely reactive species, or they can be long-living, isolable, and storable. They gain stability from filled $\mathrm{p}$ orbitals or $\pi$-systems $\alpha$ to a $s p^{2}$ hybridized carbon, which creates resonance and delocalizes the positive charge over multiple atoms (Figure 2A). Their thermodynamic stability can be described in term of their $\mathrm{p} K_{\mathrm{R}}{ }^{+}$value, which is defined by the equilibrium between the cationic species and its corresponding carbinol (Figure 2C; Deno et al., 1955) A larger $\mathrm{p} K_{\mathrm{R}}{ }^{+}$value correlates to a more stable carbenium or, specifically, one that is resistant to nucleophilic attack by water. Examples of persistent carbenium ions and their $\mathrm{pK}_{\mathrm{R}}{ }^{+}$values are shown below (Figure 2D; Breslow and Chang, 1961; Ritchie, 1986; Amyes et al., 1992; Sørensen et al., 2014).

\section{GENERAL BONDING CONSIDERATIONS}

The bonding mode for most of the Z-type ligands described in the literature is unambiguous (Amgoune and Bourissou, 2011; Owen, 2012). In these models, there is a localized empty p orbital that acts as a $\sigma$-acceptor for a filled metal-based d orbital on either a group 13 or a hypervalent, heavy group 14 element (Figure 1A). However, this bonding model becomes more complicated when considering carbocation-containing species since the empty $s p^{2}$ hybridized orbital is often involved in an extended $\pi$-system that can act as an L- or X-type ligand. In order to discuss the bonding model of carbocations in depth, it is important to remind the reader about an important concept-donation and backdonation. This concept is represented by the DewarChatt-Duncanson model (Figure 3A) with regard to metal-olefin interactions (Nelson et al., 1969; Mingos, 2001; Frenking, 2002). The filled $\pi$-orbital of the olefin donates electron density to the metal center via an interaction with an empty metal-based d orbital. This donation (L-type) is supplemented by backdonation from a filled metal-based d orbital into the empty $\pi^{*}$-orbital (Ztype). Figure 3A shows how the complex can be described either as a metal-olefin adduct from modest backbonding (resulting in an L-type ligand), or as a metallacyclopropane derivative due to extensive backbonding (where the olefin serves as an $\mathrm{LZ}$ ligand, otherwise known as an $\mathrm{X}_{2}$ ligand). The equivalence 
A

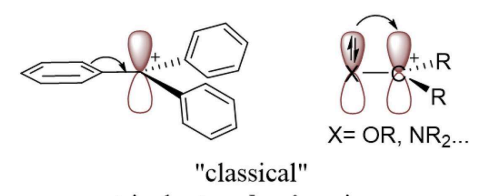

trivalent carbenium ions
B

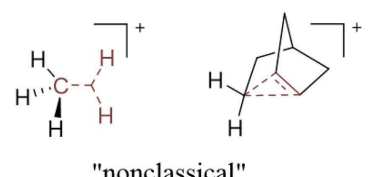

pentavalent (or higher) carbonium ions 3-center-2electron bonds

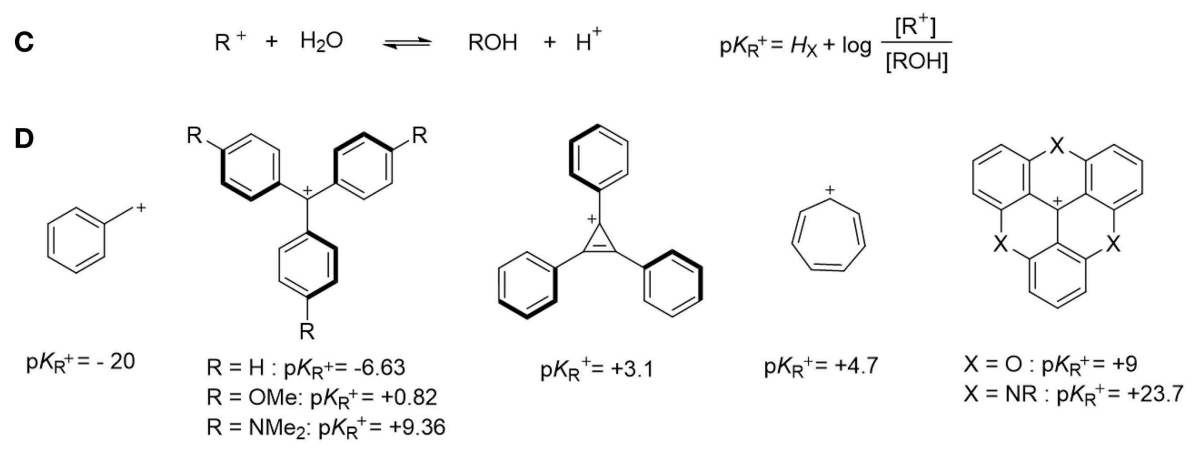

FIGURE 2 | (A) Examples of carbenium ions. (B) Examples of carbonium species. (C) Determination of carbocation stability: pK $K_{R+}$. (D) Examples of carbocations and their $\mathrm{p} K_{\mathrm{R}}{ }^{+}$values (Breslow and Chang, 1961; Ritchie, 1986; Amyes et al., 1992; Sørensen et al., 2014).

between an $\mathrm{LZ}$ and $\mathrm{X}_{2}$ system comes from the fact that both types require the involvement of two metal orbitals (Figure 3B; Parkin, 2007). Similar to the relationship between Fischer carbenes and Schrock alkylidenes (Fischer, 1976; Schrock, 2001, 2005; Shrock, 2002), the "triplet" state of the ligand becomes accessible only if the empty orbital is sufficiently low in energy. However, both bonding descriptions represent extreme cases of this model and most reported olefin complexes are more accurately described as a hybrid, with varying degrees of backdonation (Figure 3A, LZ'). The extent of backdonation strongly depends on the nature of the metal center. For example, a metal with a pair of electrons residing in a high energy orbital will favor strong backbonding interactions because of energy matching. Since it is impossible to predict which model is preferred without further spectroscopic or structural analysis, Parkin introduced the LZ' designation, where $Z^{\prime}$ refers to an unspecified degree of backbonding (Parkin, 2007). Examples of these types of ligands are $\mathrm{C}_{2} \mathrm{H}_{4}$ and $\mathrm{CO}$. In order to describe the bonding mode for carbocation-containing ligands, we will employ this $Z^{\prime}$ classification.

Another important concept is the equivalent neutral class (Figure 3C; Parkin, 2007) the classification of the ligand changes with the presence of any charge or delocalization of charge. A donor ligand with $\mathrm{x}$-electrons bound to a cationic metal center is equivalent to a donor ligand (x-1)-electrons bound to a neutral metal center (i.e., $[\mathrm{ML}]^{+} \equiv[\mathrm{MX}]$, so $\mathrm{X}^{+} \equiv \mathrm{Z}$ ). Due to the cationic nature of the ligand of interest, this notation will be used to differentiate between partial backdonation (Z') and strong backdonation/charge delocalization $\left(\mathrm{X}^{+}\right)$.

Carbocation species can form either $\sigma$ - or $\pi$-complexes depending on whether they are carbenylium $\left(\mathrm{R}_{2} \mathrm{C}^{+}\right)$or carbenium $\left(\mathrm{R}_{3} \mathrm{C}^{+}\right)$moieties. Carbenylium $\mathrm{R}_{2} \mathrm{C}^{+}$ions possess a half-filled $s p^{2}$ orbital that can participate in $\sigma$-bonding with a metal center. They also have an empty $\mathrm{p}$ orbital, which is available for backdonation (Figure 4A). Using the CBC method, $\mathrm{R}_{2} \mathrm{C}^{+}$can be described as an $\mathrm{XZ}^{\prime}$ ligand. These molecules are analogous to $\mathrm{LZ}^{\prime}$ carbenes $\mathrm{R}_{2} \mathrm{C}$ : (vide supra, $\mathrm{L}^{+} \rightarrow \mathrm{X}$ ). These carbenes can be classified in two ways, depending on the extent of $\pi$-backbonding from the metal center: either as a "Fischer carbene," which is an L-type ligand due to weak backdonation, or as a "Schrock alkylidene," which is an $\mathrm{X}_{2}$ ligand because of strong backdonation (Parkin, 2007). A similar description for the interaction between a carbenylium $\mathrm{R}_{2} \mathrm{C}^{+}$and a metal center can be used that also depends on the extent of $\pi$-backdonation. Stabilization of the empty p orbital by an alkyl substituent will result in no backdonation; in this case, $\mathrm{R}_{2} \mathrm{C}^{+}$is a pure $\mathrm{X}$ ligand (i.e., $\mathrm{X}=\mathrm{L}^{+}$for comparison with a Fischer carbene). On the other hand, no stabilization results in extensive backbonding so that $\mathrm{R}_{2} \mathrm{C}^{+}$is classified as and $\mathrm{XZ}$ ligand (i.e., $\mathrm{XZ}=\mathrm{X}_{2}+$ for comparison with a Schrock alkylidene). Types of interactions between these extreme configurations can also be observed ( $\mathrm{XZ}^{\prime}$ function, Figure 3A), as illustrated by our olefin model.

Carbenium $\mathrm{R}_{3} \mathrm{C}^{+}$moieties only possess an empty $\mathrm{p}$ orbital, resulting in the formation of $\pi$-complexes (Figure 4B). For consistency in our discussion, we describe their bonding modes, differentiated by the extent of interaction between the metal orbitals and carbon's empty $2 \mathrm{p}$ orbitals. These modes of interaction range from: (1) no $\mathrm{C}^{+}$interaction, (2) weak interactions, and (3) full hybridization of the carbon. The persistent carbenium ions that will be discussed are stabilized by resonance with an adjacent $\pi$-system. Therefore, the ligand is considered ambiphilic, since it acts both as a $\sigma$-donor through its electron rich $\pi$-system (L-type ligand) and as a $\pi$ and/or $\sigma$-acceptor through its empty $\pi^{*}$-system and $\mathrm{p}$ orbital (Z-type ligand). Again, the bonding mode depends on the electron 


\section{A Chatt-Dewar-Duncanson model}

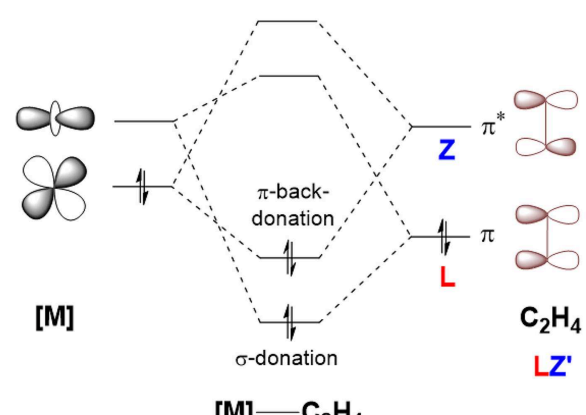

$[\mathrm{M}]-\mathrm{C}_{2} \mathrm{H}_{4}$

B Equivalence between $L Z$ and $X_{2}$

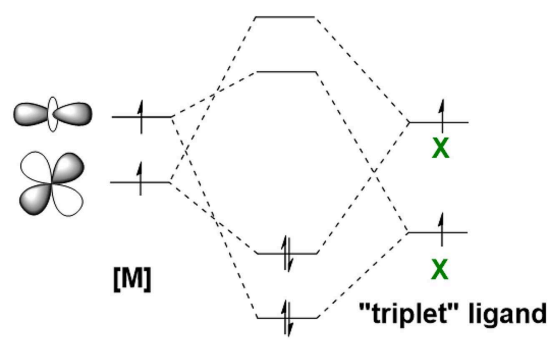

C Equivalence ionic / neutral
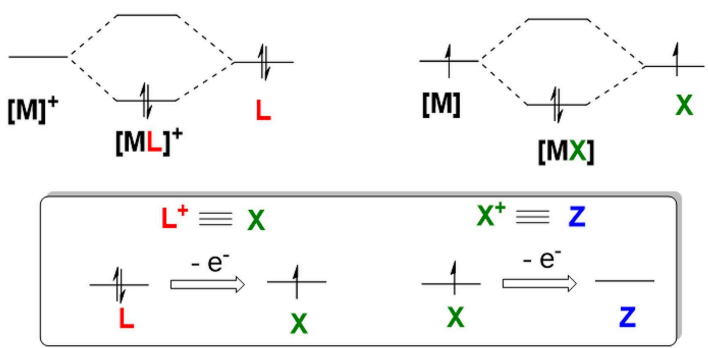

FIGURE 3 | (A) Chatt-Deward-Duncanson model. (B,C) Covalent bond classification equivalency.

A $\sigma$-complexes: $X Z$ ' ligand

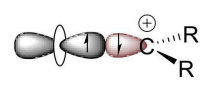

$\sigma$-donor

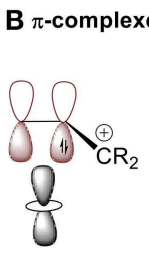

$\sigma$-donor

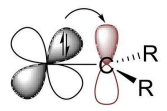

$\pi$-acceptor
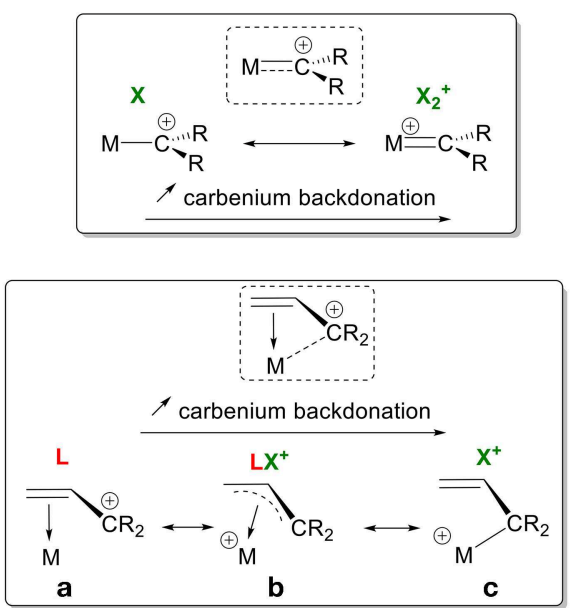

FIGURE 4 | Orbital interactions between a carbenium ion and a metal center in (A) $\sigma$-complexes, (B) $\pi$-complexes.

accepting ability of the ligand framework. In the absence of $\sigma$-backdonation from the metal, the carbenium species acts as an L-type ligand and does not interact with the metal center. In the absence of $\sigma$-backdonation from the carbenium, interactions between the filled $\pi$-system and the metal center will be the main orbital interactions, leading to a $\eta^{2}$ coordination mode with an L-type ligand (Figure 4B,a). As the interaction between the metal and the empty $\mathrm{p}$ orbital of the carbenium increases, the allyl cation acts as an $\mathrm{LX}^{+}$ligand through $\pi$ - and/or $\sigma$-backdonation, resulting in $\eta^{3}$ bonding (Figure 4B,b). In the presence of extended $\sigma$-backbonding into the $\mathrm{p}$ orbital of $\mathrm{R}_{3} \mathrm{C}^{+}$, the $\mathrm{M}-\mathrm{C}^{+}$interaction will govern the bonding mode leading to full hybridization of the carbon and a $\eta^{1}$ coordination mode (Figure 4B,c). This simplistic model is used to introduce the notion of $Z^{\prime}$ and relative backdonation into carbenium $\pi$ complexes. A more relevant bonding view of each example system will be further discussed in their corresponding sections. This will allow us to address how the $Z^{\prime}$ character of a carbenium 
ligand is affected by the nature of the metal, its d electron count, its coordination environment, and the $\pi$-systems that stabilize the $\mathrm{C}^{+}$atom.

\section{$\sigma$-COMPLEXES}

As stated in the initial bonding discussion, $\sigma$-bonded carbenium complexes are in equilibrium with a carbene-bonded cationic metal. Carbenylium cations and Fisher carbenes have similar bonding modes and are considered $\pi$-acceptors. By analogy, cyclopropenylium ions are XZ'-type ligands and Fisher carbenes are LZ'type. However, carbocations donate one electron as $\sigma$ donors while carbenes donate two electrons as $\sigma$-donors. Carbene complexes are prevalent, well-discussed species in literature so we will not focus on presenting the extensive progress in the field of carbene chemistry. Interested readers are encouraged to review articles on this subject (Ofele et al., 2009; Melaimi et al., 2010; Martin et al., 2011; Moerdyk and Bielawski, 2013). Instead, we will use selected examples to generalize bonding interactions between carbenium ions and metal centers in a $\sigma$-manner, and highlight how this bonding model is affected by the nature of the R groups on the carbenium and the metal and its ligands $\left(L_{n}\right)$.

\section{Cyclopropenylium Cations}

Cyclopropenylium cation $\left(\mathrm{C}_{3} \mathrm{H}_{3}{ }^{+}\right)$is the smallest member of the Hückel aromatic system (Breslow, 1957; Breslow and Chang, 1961). It exhibits considerable thermodynamic stability from aromaticity and resonance with $2 \pi$-electrons delocalized over three conjugated $2 \mathrm{p}$ orbitals. The symmetry of its $\pi$-system imparts enormous stability relative to typical carbocations. Its protonated analog, cyclopropene, is a strained threemembered ring that is hugely thermodynamically unstable. The stability of the cation relative to the instability of the neutral species has elicited great interest in chemists and inspired synthetic and theoretical studies for decades. Cyclopropenylium cations were first synthesized by Breslow (1957) when he synthesized triphenylcyclopropenylium cation (Breslow, 1957). This was the first experimental verification of aromaticity in non-benzenoid molecules and it offered an important lesson: the energetic debt from ring strain can be compensated by aromatic stability (Breslow and Chang, 1961). Although the cation has been widely investigated since its discovery, the number of metal-bound cyclopropenylium complexes is not as abundant. A thorough review of this topic was presented by Komatsu and Kitagawa (2003).

The first isolated $\sigma$-bound cyclopropenylium-metal complexes were reported in 1978 in consecutive articles by Gompper and Bartmann (1978) and by Weiss and Priesner (1978) following two different approaches.

Approach 1: Bartmann reported the synthesis of dicarbonyl ( $\eta$-cyclopentadienyl)( $\sigma$-2,3-diphenylcyclopropenyl)iron salts 2 from the nucleophilic attack of a coordinatively unsaturated metallate, sodium dicarbonyl( $\eta$-cyclopentadienyl)ferrate salt, to various cylcopropenium ions 1 (Figure 5A). While the formation of $\mathrm{NaX}$ ( $\mathrm{X}=$ cyclopropenium counter ions) is a strong driving force for this reaction, the neutral compound $\mathbf{2}$ is highly strained and reactive from loss of aromaticity. Stability from aromaticity was easily restored by abstraction of the $\mathrm{R}_{2}$ group (e.g., $\mathrm{Ph}, \mathrm{He}, \mathrm{H}$, $\mathrm{Cl}$ ) with appropriate abstracting agent $\mathrm{E}$ (e.g., $\mathrm{HCl}, \mathrm{I}_{2}$, $\left.\left[(\mathrm{Ph})_{3} \mathrm{C}^{+}\right]\left[\mathrm{BF}_{4}^{-}\right]\right)$, resulting in the $\sigma$-bound cyclopropenylium ion complexes 3 (Gompper and Bartmann, 1978).

Approach 2: Weiss and Priesner proposed that the neutral cyclopropenylidene complex 4, first reported by Öfele (1970), is in resonance with the Zwitterionic form 5, where a metallate anion is bound to a cyclopropenylium moiety (Figure $\mathbf{5 B}$; Weiss and Priesner, 1978). With the aid of a strong Lewis acid, bound anionic ligand $\mathrm{X}^{-}$can be exchanged with a noncoordinating anion (e.g., - OTf), leading to the formation of transition metal-substituted cyclopropenylium system 6 . A variety of cyclopropenylidene complexes have since been reported. Their synthesis typically follows one of three routes: (1) oxidative addition of dihalocyclypropenes followed by halide abstraction (Öfele, 1970; Konishi et al., 1978; Weiss and Priesner, 1978; Yoshida, 1982; Miki et al., 1988), (2) reaction of the cyclopropenyl salts with lithium adducts (Rees and von Angerer, 1972; Gompper and Bartmann, 1978; Konishi et al., 1978; Yoshida, 1982; Miki et al., 1988; Tamm et al., 1995; Schumann et al., 1997), or (3) cyclopropenylidene transfer (Yoshida, 1982; Gade et al., 2000; Kozma et al., 2013). These carbene species have been extensively discussed and were thoroughly reviewed by Herrmann in 2009 (Ofele et al., 2009). The bonding mode of cyclopropenylidene complexes is unambiguous and well-established by carbene chemistry and, therefore, will not be presented in this review.

As discussed, the extent of $\pi$-backdonation depends on the energies of the overlapping orbitals. Substituents on the ring alter the XZ bonding mode for this ligand because of the impact they have on the extent of electron donation and $\pi$ backdonation to the ring. In their initial report, Gompper and Bartmann synthesized complexes of substituted cyclopropenium ions with $\left[\mathrm{Fe}(\mathrm{Cp})(\mathrm{CO})_{2}\right]$ (Gompper and Bartmann, 1978). They measured strength of the interaction between the iron atom and the carbon atom of the $\mathrm{C}_{3}$ ring with IR spectroscopy and found the stretching frequencies of the $\mathrm{CO}$ moiety bound to iron in 3a-c showed a clear blueshift of the $v_{(\mathrm{CO})}$ between $\mathrm{R}$ $=\mathrm{Ph}, \mathrm{R}={ }^{t} \mathrm{Bu}$, to $\mathrm{R}=\mathrm{NEt}_{2}$ (Figure $5 \mathrm{C}$ ), which is consistent with a decrease in $\pi$-backdonation from the metal into the $\mathrm{CO}$ ligand. This decreased electron density on the metal center is a result of the increased $\pi$-accepting ability of cyclopropenylium ligand, which correlates to a lower $\mathrm{pK}_{\mathrm{R}}^{+}$value (Figure $5 \mathrm{C}$ ). These trends support the XZ-type bonding model discussed in the first part of this review (vide supra, Figure 4A) and is analogous to the cyclopropenylidene complexes summarized in Herrmann's review: complexes bearing cyclopropenylidene ligands with two amino substituents showed the most $\sigma$-donor/least $\pi$-acceptor ability, and those containing two phenyl groups show the least $\sigma$-donor/most $\pi$-acceptor ability (Ofele et al., 2009).

This also supports our claim that that $\mathrm{CR}_{2}{ }^{+}$acts as an $\mathrm{XZ}^{\prime}$ ligand with different degrees of Z-type interactions. More precisely, complexes with $\mathrm{C}\left(\mathrm{C}\left(\mathrm{NR}_{2}\right)_{2}\right)_{2}{ }^{+}$ligands are best described as X-type ligands with little or no $\pi$-backdonation, 
A<smiles>[R]C1=C([R])C1[R]</smiles>

B<smiles>[R20]C1=C([R10])C1=[Y4]</smiles><smiles>[Y10]C1C([Y10])N1[R12]</smiles>

5

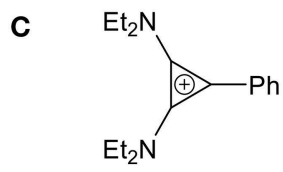

$\mathrm{pK}_{\mathrm{R}}^{+}>+10$

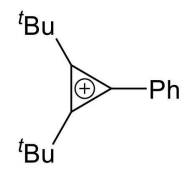

$\mathrm{pK}_{\mathrm{R}}^{+}=+4.9$
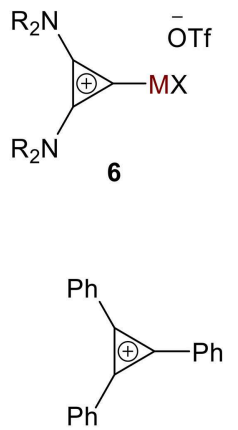

$\mathrm{pK}_{\mathrm{R}}^{+}=+3.1$
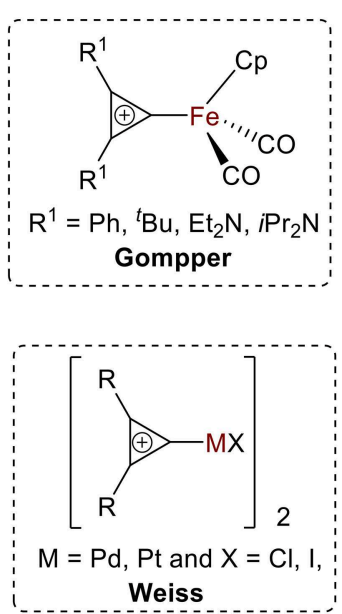

increasing $\pi$-accepting

(stronger Z' ligand)

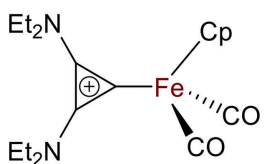

$3 a$

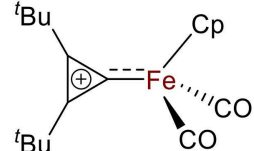

$3 b$

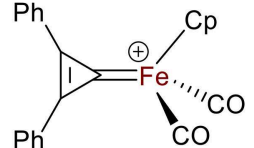

3c

$v C O=2035,1973 \mathrm{~cm}^{-1} \quad v C O=2042,2000 \mathrm{~cm}^{-1} \quad v C O=2045,2005 \mathrm{~cm}^{-1}$

FIGURE 5 | General synthesis for cyclopropenylium complexes: (A) Approach 1, (B) Approach 2. (C) Influence of the ring substituent on the extent of back donation.

while complexes containing $+\mathrm{C}\left(\mathrm{CPh}_{2}\right)_{2}$ ligands are more appropriately represented as $\mathrm{X}_{2}{ }^{+}$ligands because of their large Z-type interaction.

\section{Arylenium Cations}

Over the past decade, cationic gold(I) complexes have become some of the most efficient and versatile catalysts for the functionalization of C-C bonds (Echavarren and Nevado, 2004; Olah, 2004; Fürstner and Davies, 2007; Hashmi and Rudolph, 2008; Li et al., 2008; Jia and Bandini, 2015; Harris and Widenhoefer, 2016; Hopkinson et al., 2016; Zi and Toste, 2016; Shahzad et al., 2017). These complexes are typically formed from gold carbenes or from $\alpha$-metallocarbenium ions. They contain a gold atom that is bound to a formally divalent carbon atom and are applied in a variety of gold-catalyzed transformations. The electronic structure of these cationic complexes is dependent on the extent of $\pi$-backbonding from the gold atom to the $\mathrm{C}_{1}$ carbon atom (Figure 6A). The bonding mode of gold carbene/carbenium complexes has been extensively discussed, and much of gold carbene complexes' behavior can be understood by applying the bonding model developed by Toste and Goddard (Benitez et al., 2009). According to this model, the $\mathrm{L}-\mathrm{Au}-\mathrm{C}$ bonding network is comprised of three sets of orbital interactions: (1) a three-center, four-electron $\sigma$-hyperbond that donates electron density from filled $s p^{\mathrm{x}}$ orbitals on the carbene's carbon atom to gold's empty $6 \mathrm{~s}$ orbital (Figure 6A,b), (2) two orthogonal $\pi$-bonds that donate electron density from the metal's filled $5 \mathrm{~d}$ orbitals to the ligand's $\pi$ acceptor orbitals (Figure 6A,a), and (3) the carbene's $\pi$-acceptor orbitals (Figure $\mathbf{6 A , c}$ ). It follows that greater $\sigma$-donation from the ligand (L) results in a weaker $\sigma$ component of the $\mathrm{Au}-$ $\mathrm{C}_{1}$ bond and greater $\pi$ acidity of the ligand results in weaker $\mathrm{Au}-\mathrm{C}_{1}$ backdonation.

Cationic gold(I) complexes have been extensively studied, so this review will focus only on what we consider to be one of the most intriguing species present during gold catalysis: the gemdiaurated carbocation species (a carbocation that is stabilized by two gold atoms through $\mathrm{Au}-\mathrm{Au}$ contacts) (Hashmi, 2014). The abundance of cationic gem-diaurated species discovered in gold-mediated catalysis (Harris and Widenhoefer, 2016) 
A

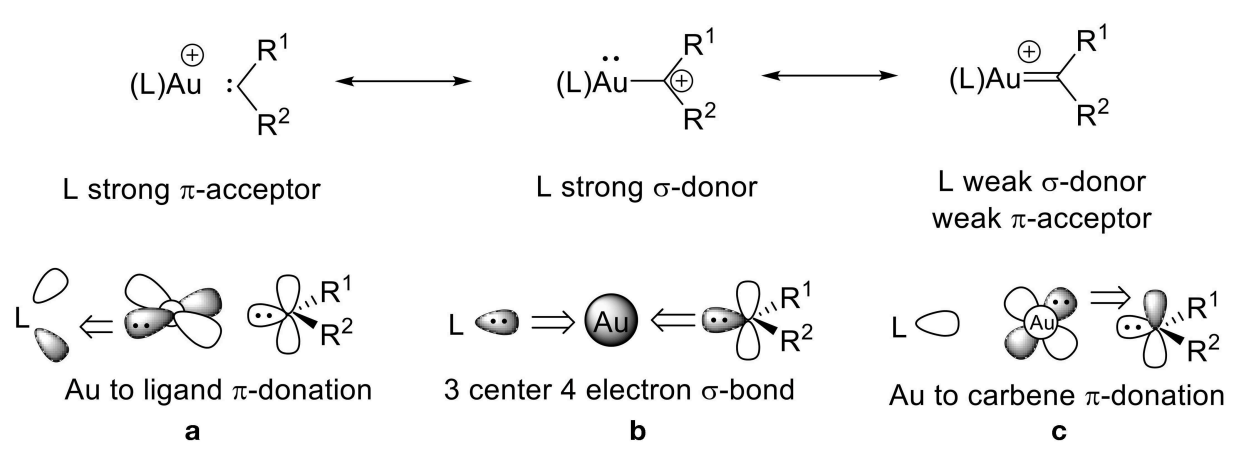

B
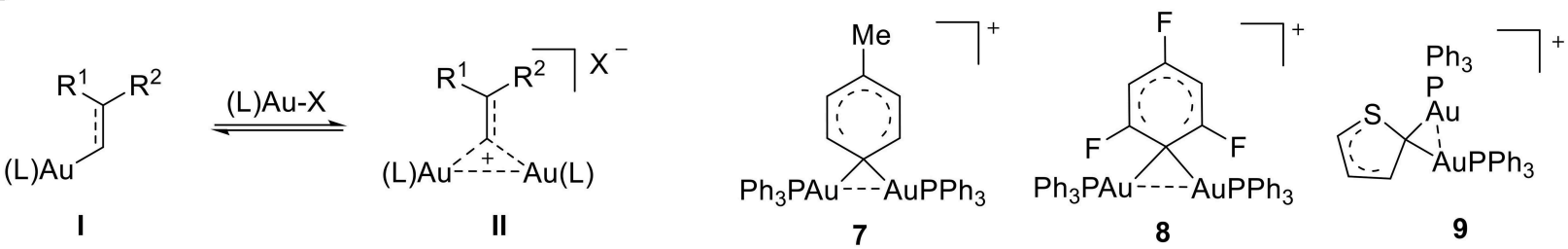

FIGURE 6 | (A) Bonding model for gold-carbene resonance structures. (B) Gem-diaurated carbocation species.

helped researchers conclude that an equilibrium exists between the vinyl gold(I) species I and the gem-diaurated species II (Figure 6B; Roithová et al., 2012; Harris and Widenhoefer, 2016). Further, the substituents $\mathrm{R}^{1}$ and $\mathrm{R}^{2}$ influence this equilibrium. A balance of stability and reactivity is required to observe this diaurated species II; otherwise, II can form a catalyst-poisoning thermodynamic sink, rendering the equilibrium irreversible (Roithová et al., 2012). In order for efficient catalysis to take place, the equilibrium must be reversible, and the gem-diaurated species II is actually a less reactive off-cycle species than the corresponding vinyl gold(I) species I (Brown et al., 2012; Zhdanko and Maier, 2013). This can be rationalized by the fact that the gem-diaurated species II is stabilized through $\mathrm{Au}-\mathrm{Au}$ interactions, which makes it less reactive than the unstabilized vinyl gold(I) species I.

The tolyl complex 7 represents the first 1,1-diaurated carbocation derived from benzene (Nesmeyanov et al., 1974) and the cation of perchlorate salt $\mathbf{8}$ provided the first crystallographic evidence for 1,1-diauration (Figure 6B; Rafael et al., 1988). According to its X-ray data, complex 8 shows an Au-C-Au bond angle of $79.3^{\circ}$, Au-C bond lengths of $2.16 \AA$, and a relatively short $\mathrm{Au} \cdots \mathrm{Au}$ distance of $2.76 \AA$. The two $\left[\mathrm{AuPPh}_{3}\right]$ units in the diaurated thienyl complex 9 have identical phosphorus environments based on the ${ }^{31} \mathrm{P} \mathrm{NMR}$, which shows only one peak. The structure includes a short $\mathrm{Au}^{\cdots}$ Au distance of $2.81 \AA$ and a small Au-C-Au angle of $82.5^{\circ}$ (Porter et al., 2003), which shows a strong aurophilic interaction (Schmidbaur, 1990; Mond et al., 1995; Stephen et al., 2012), that is consistent with other reports of diaurated compounds (Osawa et al., 2008; Seidel et al., 2010). The literature range of $\mathrm{Au}$-Au distances for gem-diaurated compounds is 2.72 to $2.85 \AA$.

\section{$\pi$-COMPLEXES}

\section{Cyclic Carbocations Cyclopropenium Cations}

The first $\pi$-complexes with cyclopropenium cation were synthesized by Hayter (1968). His brief report included the synthesis of only one cyclopropenium-ligated complex, $[(\pi-$ $\left.\left.\mathrm{C}_{5} \mathrm{H}_{5}\right) \mathrm{Mo}\left(\pi-\mathrm{C}_{3} \mathrm{Ph}_{3}\right)(\mathrm{CO})_{2}\right]$, and its characterization by ${ }^{1} \mathrm{H}$ NMR. The NMR spectrum showed a complex multiplet centered at $\delta=7.2 \mathrm{ppm}$ with peak intensity ratio 5:17 for the phenyl substituents of the cyclopropenium ring (Hayter, 1968). Since Hayter's report, other isolated cyclopropenylium-metal complexes were reported; Komatsu et al. summarized these in an extensive review published in 2003 (Komatsu and Kitagawa, 2003). To the best of our knowledge, no new $\pi$-complexes of this type have since been reported.

The reactions of cyclopropenylium cations with low valent metal centers can lead to ( $\eta^{3}$-cyclopropenyl)- (Chiang et al., 1979; Hughes et al., 1986, 1993; Lichtenberger et al., 1993; Ghilardi et al., 1995), ( $\eta^{2}$-cyclopropenyl)- (Mealli et al., 1982), and ( $\eta^{1}$-cyclopropenyl) (Gompper and Bartmann, 1985) metal complexes. The hapticity of the product depends on the ring's substituents, the metal, and the other ligands on the metal (Figure 7).

To better understand which coordination mode will be favored in each of these complex types, the molecular diagrams of $\mathrm{C}_{3} \mathrm{R}_{3}$ and the frontier orbitals for $\mathrm{ML}_{\mathrm{n}}$ fragment $(n=2-$ 5) (Jorgensen and Salem, 1973) are shown in Figures 8A,B respectively. The cyclopropenyl ring can either act as a: (1) $\sigma$ donor with its filled $\mathrm{a}_{2}{ }^{\prime \prime}$ orbital; (2) $\pi$-acceptor with its empty $\mathrm{e}^{\prime \prime}$ orbital, if bound in an $\eta^{2}$ or $\eta^{3}$ coordination mode; or 


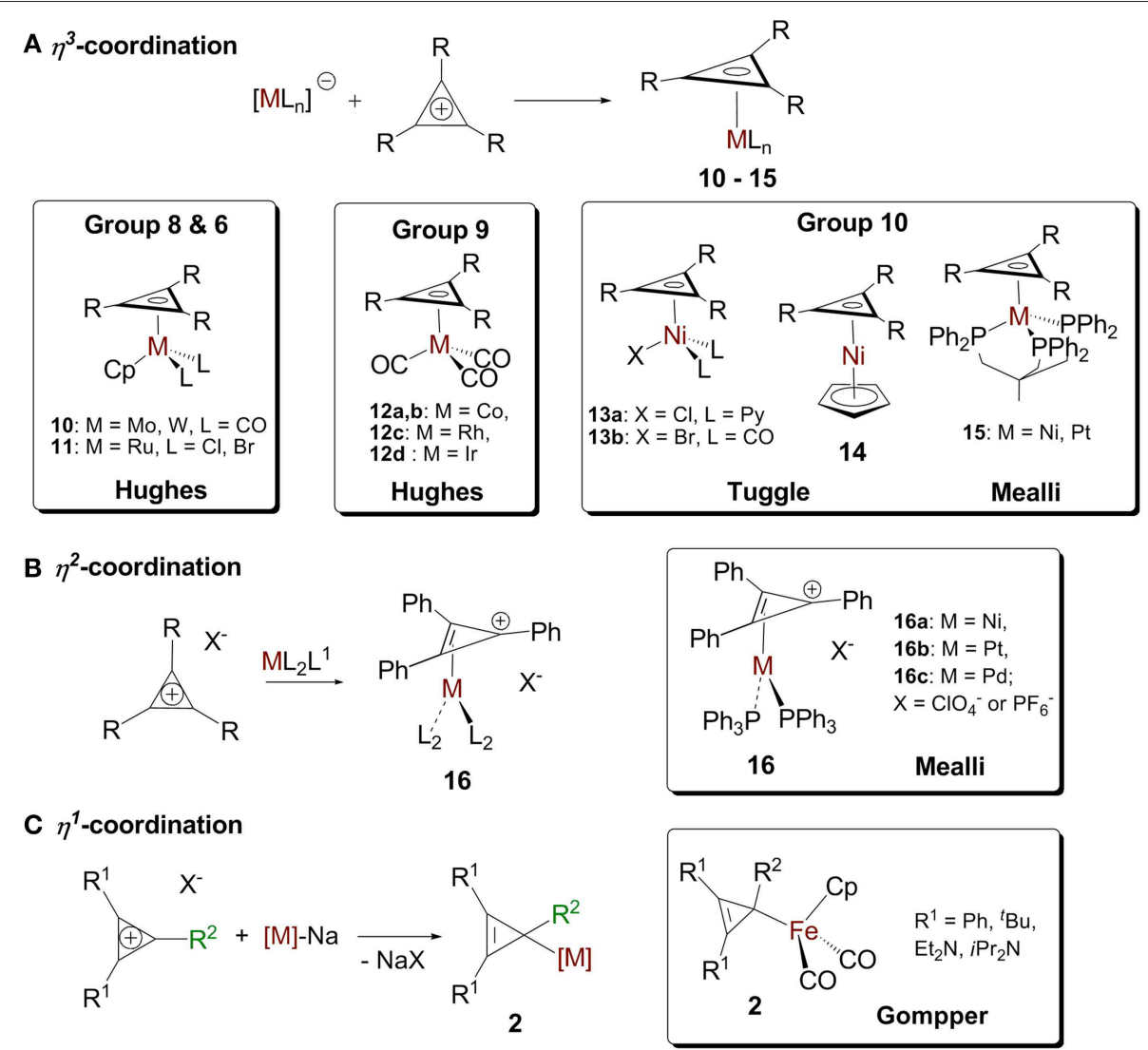

FIGURE 7 | (A) $\eta^{3}$-cyclopropenium complex. (B) $\mathrm{d}^{10}\left(\eta^{2}\right.$-cyclopropenium) $\mathrm{ML}_{2}$ complex and the "Ring-whizzing" phenomenon. (C) $\eta^{1}$-cyclopropenium complex.

(3) $\sigma$-acceptor with one of the empty $e^{\prime \prime}$ orbitals if bound in an $\eta^{1}$ fashion. The coordination mode and the ring-metal interaction are determined by the $\mathrm{d}$ electron count of the metal and by the ligand environment of the metal fragment as established by a molecular orbital approach developed by Hoffmann et al. (Jemmis and Hoffmann, 1980). In short, the ML group will adopt the position that maximizes stabilizing bonding interactions. For the following discussion, the molecules will be arbitrarily split into neutral fragments, $C_{3} R_{3}$ and $M L_{n}$.

\section{$\eta^{3}$ coordination}

Cyclopropenium-metal complexes are prepared from the reaction between a cyclopropenium cation and a metal precursor, often a salt leading to the formation of a neutral species (Figure 7A; Donaldson and Hughes, 1982). We will model $\eta^{3}$ coordination in cyclopropenium complexes with an $\mathrm{ML}_{3} \mathrm{~d}^{9}$ fragment, $\mathrm{Co}(\mathrm{CO})_{3}$. When the $\mathrm{ML}_{3}$ fragment is bound to the ring in this way (Figure 8c.1), the $\mathrm{a}_{2}{ }^{\prime \prime}$ and $\mathrm{e}^{\prime \prime}$ orbitals of the cyclopropenium moiety are symmetrical to the high-lying empty $2 \mathrm{a}_{1}$ orbital and the partially filled $2 \mathrm{e}$ orbital. In this case, coordination will optimize the number of metal-ring interactions, resulting in one $\sigma$ - and two $\pi$-orbital interactions. If the $\left[\mathrm{Co}(\mathrm{CO})_{3}\right]^{-}$fragment moves off of the center of the ring and coordinates to it differently, part of the $\pi$-backdonation between the e orbitals will be lost. Evidence of the $\eta^{3}$ bonding model for
$\left(\mathrm{C}_{3} \mathrm{R}_{3}\right) \mathrm{Co}(\mathrm{CO})_{3}$ was confirmed experimentally by Lichtenberger et al. by photoelectron spectroscopy (Lichtenberger et al., 1993). This bonding model is applicable to complexes with the general formulas $\left(\mathrm{C}_{3} \mathrm{R}_{3}\right) \mathrm{ML}_{3}$ (where $\mathrm{M}=\mathrm{Co}, \mathrm{Rh}, \mathrm{Ir}$ ) (Chiang et al., 1979) and $\left(\mathrm{C}_{3} \mathrm{R}_{3}\right) \mathrm{ML}_{2} \mathrm{X}$ (where $\mathrm{M}=\mathrm{Ni}, \mathrm{Pt}, \mathrm{Pd} ; \mathrm{X}=$ anionic ligand; $\mathrm{L}=$ neutral ligand) (Mealli et al., 1981, 1983; Miki et al., 1988; Kuchenbeiser et al., 2008). Since $\mathrm{d}^{9} \mathrm{ML}_{3}$ and $\mathrm{d}^{5} \mathrm{ML}_{5}$ complexes are isolobal, this $\eta^{3}$ bonding is also appropriate for complexes with the general formula $\left(\mathrm{C}_{3} \mathrm{R}_{3}\right) \mathrm{ML}_{3} \mathrm{X}_{2}$ (where $\mathrm{M}$ $=\mathrm{Ru}$ ) (Ditchfield et al., 1993; Morton and Selegue, 1999) and $\left(\mathrm{C}_{3} \mathrm{R}_{3}\right) \mathrm{ML}_{4} \mathrm{X}$ (where $\mathrm{M}=$ Mo or W) (Hayter, 1968; Drew et al., 1981; Hughes et al., 1985).

In general, the bonding mode in cyclopropenium-transition metal complexes depends on the metal involved. Strong $\pi$ backdonation from the metal to the carbocation increases the Z-type character of the ligand. It follows, then, that the distance between the metal and the $C_{3}$ ring decreases while the $\Delta G^{\ddagger}$ of rotation around their bond increases. If the metal in one of these complexes is coordinated to CO ligands, the bond between the metal and $\mathrm{CO}$ ligand increases in length, which results in a distinct shift in the $v_{(\mathrm{CO})}$ relative to that of the free COcoordinated metal complex.

Infrared spectroscopy is the most powerful tool for monitoring reactions of metal carbonyls and for assignment of their structures, since the $v_{(\mathrm{CO})}$ absorptions are easily 


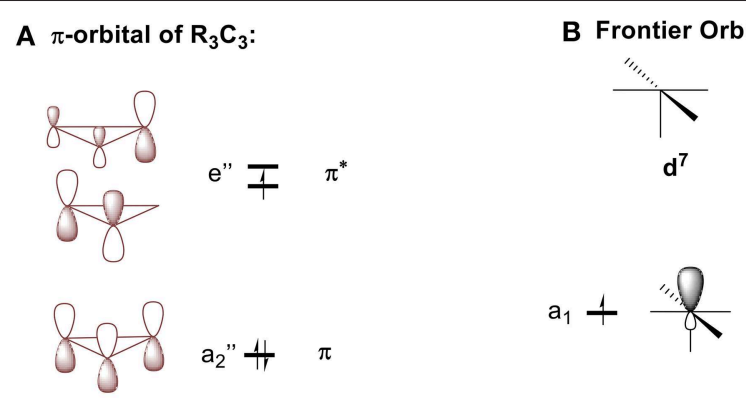

C Frontier orbitals interaction for $\mathbf{M}-\mathbf{R}_{3} \mathrm{C}_{3}$ : c.1 $\eta^{3}$-coordination

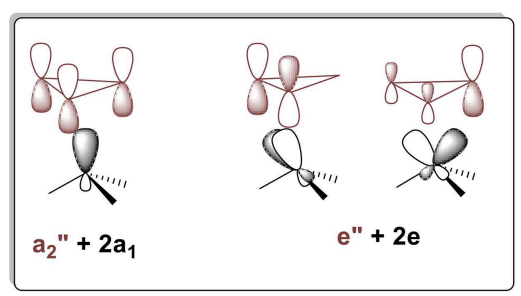

B Frontier Orbitals for $\mathrm{ML}_{\mathrm{n}}(\mathrm{n}=5,3,2)$ :

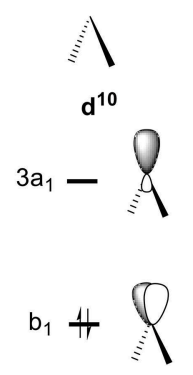

c.3 $\eta^{1}$-coordination

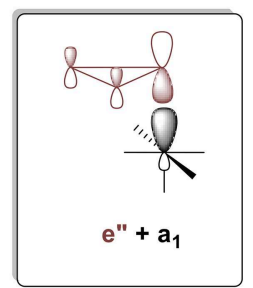

FIGURE 8 | Descritpion of bonding mode between cyclopropenium and metal fragments. (A) $\pi$-orbital of $R_{3} C_{3}$. (B) Frontier orbitals $M L_{n}(n=5,3,2)$. (C) Frontier orbitals interaction for $\mathrm{M}-\mathrm{R}_{3} \mathrm{C}_{3}$ : (c.1) $\eta^{3}$-coordination, (c.2) $\eta^{2}$-coordination, (c.3) $\eta^{1}$-coordination.

TABLE 1 | Compiled $M-C_{3}$ ring distance data (Churchill et al., 1984) and IR frequencies for CO in selected $\pi$-complexes.

\begin{tabular}{|c|c|c|c|}
\hline & $\underbrace{\mathrm{R}}_{\mathrm{ML}_{\mathrm{n}}}$ & $\begin{array}{l}{ }^{t}{ }^{t} \mathrm{Bu} \\
\mathrm{pK}_{\mathrm{R}}{ }^{+}=+6.5\end{array}$ & $\begin{array}{l}-\mathrm{NR}_{2} \\
+13\end{array}$ \\
\hline Complex & $M-C_{3}$ centroid distance $(\AA)$ & $v_{(\mathrm{CO})} \mathrm{cm}^{-1}$ & Metal $v_{(\mathbf{C O})} \mathbf{~ c m}^{-\mathbf{1}}$ (Ellis, 2003) \\
\hline 12a: $\mathrm{Co}\left(\mathrm{C}_{3} \mathrm{Ph}_{3}\right)(\mathrm{CO})_{3}$ & 2.01 (Chiang et al., 1979) & 2,080, 2,040 (Hughes et al., 1993) & {$\left[\mathrm{Co}(\mathrm{CO})_{4}\right]^{-}=1,888$} \\
\hline 12b: $\mathrm{Co}\left(\mathrm{C}_{3}{ }^{t} \mathrm{Bu}_{3}\right)(\mathrm{CO})_{3}$ & - & 2,046, 1,976 (Hughes et al., 1993) & \\
\hline 12c: $\operatorname{Rh}\left(\mathrm{C}_{3}{ }^{t} \mathrm{Bu}_{3}\right)(\mathrm{CO})_{3}$ & - & 2,055, 1,991 (Hughes et al., 1993) & {$\left[\mathrm{Rh}(\mathrm{CO})_{4}\right]^{-}=1,895$} \\
\hline 12d: $\operatorname{lr}\left(\mathrm{C}_{3}{ }^{t} \mathrm{Bu}_{3}\right)(\mathrm{CO})_{3}$ & 2.02 (Hughes et al., 1993) & 2,053, 1,985 (Shen et al., 1993) & {$\left[\operatorname{Ir}(\mathrm{CO})_{4}\right]^{-}=1,895$} \\
\hline 13a: $\mathrm{Ni}\left(\mathrm{C}_{3} \mathrm{Ph}_{3}\right) \mathrm{Cl}(\mathrm{py})_{2}$ & 1.94 (Tuggle and Weaver, 1971a) & & \\
\hline
\end{tabular}

altered by changes to the molecular structure and charge of a carbonyl complex. It is unsurprising, then, that ion pairing between the cyclopropenium cation and a metal carbonyl anion results in significant changes in the $v_{(\mathrm{CO})}$ region, due to strong perturbation of the geometry of the anion. This characteristic is the result of $\pi$-backbonding, since $\mathrm{CO}$ is a $\pi$-acceptor ligand. When the $v_{(\mathrm{CO})}$ decreases as a result of decreasing bond strength, the strength of the $\mathrm{M}-\mathrm{C}$ bond increases. As the $\mathrm{M}-\mathrm{C}_{3}$ distance decreases, the $\mathrm{M}-\mathrm{CO}$ distance increases; therefore, a longer $\mathrm{M}-\mathrm{C}_{3}$ distance corresponds to a shorter $\mathrm{M}$-CO distance and a decrease in $v_{(\mathrm{CO})}$ relative to free $\mathrm{CO}\left(2143 \mathrm{~cm}^{-1}\right)$.
The $v_{(\mathrm{CO})}$ of a complex is affected by the nature of the substituents on the $\mathrm{C}_{3}$ ring (Table 1). When the ring substituents are changed from phenyls to t-butyls in the otherwise identical cobalt carbonyl complexes (12a and $\mathbf{1 2 b}$, respectively), the $v_{(\mathrm{CO})}$ decreases and the metal-centroid bond distance increase significantly as a result of the increase in electron donation from the substituent, consistent with an increase in $\mathrm{pK}_{\mathrm{R}}{ }^{+}$values (Table 1). It is worth mentioning that no metal complexes are reported with tris(amino)cyclopropenylium cations, suggesting that these are inadequately $\pi$-accepting (Table $1, \mathrm{pK}_{\mathrm{R}}{ }^{+}>10$ ) (Ciabattoni and Nathan, 1969; Moss et al., 1986; Bandar and 
Lambert, 2013; Jiang et al., 2015). The nature of the metal also affects the electronic configuration of the complex (Table 1). As expected, larger metals (Co to Ir in complexes $\mathbf{1 2 b - 1 2 d}$ ) provide better orbital overlap. More $\pi$-donation between the metal and the ring is observed from Co to Ir, which is consistent with the increase in $v_{(\mathrm{CO})}$. Finally, the extent of the back donation from the metal to the ring is dependent on the $\pi$-accepting ability of the other ligand bound to the metal. The nickel complexes in the table below (13a, 14, and 15) illustrate this: the trisphosphine (15) is a stronger $\pi$-accepting ligand than either $\mathrm{Cp}$ or two pyridines and a chloride (14 and 13a, respectively), and an increase in the $\mathrm{M}-\mathrm{C}_{\text {centroid }}$ is observed. This suggests that the backdonation into the $\mathrm{C}_{3}$ ring is most significant in 13a.

Tuggle and Weaver determined an important factor of the electronic transitions in their $\left[\left(\pi-\mathrm{Ph}_{3} \mathrm{C}_{3}\right) \mathrm{NiCl}(\mathrm{py})_{2}\right] \cdot \mathrm{py}$ compound 10c by comparing the UV-Vis spectra of their metal complex to that of the free ligand. Since the spectra showed no appreciable differences in their $\pi \rightarrow \pi^{*}$ transitions, they concluded the principle bonding interaction in the metal complex is not involved in the $\pi \rightarrow \pi^{*}$ transition (Tuggle and Weaver, 1971a). Later, they studied an analogous mixed nickel sandwich 11, $\left[\left(\pi-\mathrm{Ph}_{3} \mathrm{C}_{3}\right) \mathrm{Ni}\left(\pi-\mathrm{C}_{5} \mathrm{H}_{5}\right)_{2}\right]$, and considered the metal's interactions with each ring separately. They presented two possibilities for the cyclopropenyl moiety's interactions were presented: 1) overlap of a hybridized metal $\mathrm{a}_{1}$ orbital (with $3 \mathrm{~d}_{\mathrm{z}}^{2}$, $4 \mathrm{~s}$, and $4 \mathrm{p}_{\mathrm{z}}$ contributions) with the $\mathrm{a}_{1}$ combination of the $\mathrm{C}_{3} \mathrm{p} \pi$ orbitals; and (2) back-donation from the metal e orbitals to the e antibonding combination of the ring $\mathrm{p} \pi$ orbitals. Importantly, they concluded that the back-donation was likely directed toward the formally positively charged $\mathrm{C}_{3}$ ring and not toward the cyclopentadiene (Tuggle and Weaver, 1971b). This finding is consistent with our conclusions above regarding $\mathrm{M}-\mathrm{C}_{3}$ distance and $v_{(\mathrm{CO})}$.

Prior studies by Hughes et al. measured the free energy of activation $\left(\Delta G^{\ddagger}\right)$ for cyclopropenium ring rotation in $\mathrm{Mo}, \mathrm{Ru}$, Co, Rh, Ir derivatives (Hughes et al., 1993), which provided quantitative correlations between electronic and steric effects of ancillary ligands. Comparison of these experimental $\Delta G^{\ddagger}$ values showed a significant increase in the rotational barrier of $\mathrm{C}_{3}$ rotation about the metal- $\mathrm{C}_{3}$ axis with descending group, which agreed with their prior findings in $\eta^{3}$ complexes (Co $<\mathrm{Rh}<$ Ir) (Hughes et al., 1993) and with general observations made for rotational barriers of olefin and 1,3-diene complexes of transition metals (Mann, 1982).

\section{$\eta^{2}$ coordination}

We will model $\eta^{2}$ coordination with a $\mathrm{d}^{10} \mathrm{ML}_{2}$ fragment, $\mathrm{Ni}\left(\mathrm{PPh}_{3}\right)_{2}$. In this case, only two frontier orbitals are suitable to interact with the ring (Figure 8c.2). According to Hoffmann and Mealli's calculations, the low energy levels consist of four closely spaced levels, $b_{2}+1 a_{1}+a_{2}+2 a_{1}$, which are identifiable with the $\mathrm{e}_{\mathrm{g}}+\mathrm{b}_{2 \mathrm{~g}}+\mathrm{a}_{1 \mathrm{~g}}$ set of typical square planar $\mathrm{ML}_{4}$ systems (not shown in Figure 8B) (Jemmis and Hoffmann, 1980; Mealli et al., 1982). Higher in energy is $b_{1}$, which is hybridized out away from the $\mathrm{L}$ groups and toward the cyclopropenium ring. Even higher in energy is $3 a_{1}$, which is cylindrically symmetrical and is also hybridized away from $\mathrm{L}$ groups. The $\mathrm{b}_{1}$ orbital is the HOMO of a $\mathrm{d}^{10} \mathrm{ML}_{2}$ fragment and the $3 \mathrm{a}_{1}$ orbital is the LUMO. The high lying empty $3 a_{1}$ orbital can interact with the filled $a_{2}{ }^{\prime \prime}$ orbital of the ring and the filled $b_{1}$ metal orbital can undergoes back donation with one of orbital of $e^{\prime \prime}$ set of the $\mathrm{C}_{3} \mathrm{R}_{3}^{+}$(Figure 8A). It is worth mentioning that $\pi$ interaction between the low lying $b_{2}$ metal orbital and the other component of the $\mathrm{e}^{\prime \prime}$ orbital is present but much weaker. The loss of this $\pi$ interaction is compensated by the metal fragment sliding in an $\eta^{2}$ coordination mode to optimize the $\pi$ interaction that involves the frontier $b_{1}$ orbital of the metal. This bonding type will described for complexes of the type $\left[\left(\mathrm{C}_{3} \mathrm{R}_{3}\right) \mathrm{ML}_{2}\right]^{+}(\mathrm{M}=\mathrm{Ni}, \mathrm{Pt}, \mathrm{Pd})$ and $\left[\left(\mathrm{C}_{3} \mathrm{R}_{3}\right) \mathrm{ML}_{4}\right]^{+}$with a $\mathrm{d}^{8}$ metal due to the isolobal relationship of $\mathrm{d}^{8} \mathrm{ML}_{4}$ and $\mathrm{d}^{10}$ $\mathrm{ML}_{2}$ complexes.

The clearest indication of $\eta^{2}$ bonding is unequal distances between the metal atom and any of the three carbons in the ring. McClure and Weaver's platinum complex in 1973 was the first report of this unsymmetrical bonding (McClure and Weaver, 1973). In their complex, 16b $\left[\mathrm{Pt}\left(\mathrm{C}_{3} \mathrm{Ph}_{3}\right)\left(\mathrm{PPh}_{3}\right)_{2}\right]\left[\mathrm{PF}_{6}\right]$ (McClure and Weaver, 1973), the $\mathrm{Pt}$ atom is $2.09 \AA$ away from 2 of the cyclopropenium carbons, while it is $2.48 \AA$ away from the third carbon. McClure concluded that his complexes are more closely related to the $\eta^{2}$-cyclopropene resonance form and less like the $\eta^{3}$ complexes Weaver synthesized earlier and that the coordination geometry and bond lengthening could be described with the bonding mode of olefins to zerovalent transition metals (McClure and Weaver, 1973).

In 1982, Mealli et al. published an important report on a phenomenon in which an $\mathrm{ML}_{n}$ unit migrates inside the periphery of a cyclic polyene. They called this unique fluxionality "ring-whizzing" (Mealli et al., 1982). Mealli compared three complexes $16\left[\left(\mathrm{Ph}_{3} \mathrm{C}_{3}\right) \mathrm{M}\left(\mathrm{PPh}_{3}\right)_{2}\right] \mathrm{X}$ (where $\mathrm{M}=\mathrm{Ni}$ (16a), $\mathrm{Pt}$ (16b)or $\mathrm{Pd}(16 \mathrm{c})$ and $\mathrm{X}=\mathrm{ClO}_{4}^{-}$or $\mathrm{PF}_{6}^{-}$) by ${ }^{13} \mathrm{C} \mathrm{NMR}$ and by computational studies informed by their X-ray structure data. They determined that the $\left(\mathrm{Ph}_{3} \mathrm{P}\right)_{2} \mathrm{M}$ unit progressively moved over the face of the cyclopropenium cation. This movement was used to chart the reaction path from one $\eta^{2}$ geometry, with the $\left(\mathrm{Ph}_{3} \mathrm{P}\right)_{2} \mathrm{M}$ unit positioned below one $\mathrm{C}-\mathrm{C}$ bond, to an equivalent $\eta^{2}$ geometry. They concluded that a smaller distance between the metal and one of the carbons in the ring resulted in increased tilting and twisting of the phenyl group directly connected to it. These geometric changes caused longer exocyclic C-C distances because of the decreased conjugation between the phenyl groups and the cyclopropenium ring (Gompper and Bartmann, 1985).

\section{$\eta^{1}$ coordination}

We will model the $\eta^{1}$ coordination mode with a $\mathrm{d}^{7} \mathrm{ML}_{5}$ fragment, $\left[\mathrm{Fe}(\mathrm{CO})_{2} \mathrm{Cp}\right]^{-}$(Gompper and Bartmann, 1978). The frontier orbital of this fragment has two electrons in the $\mathrm{a}_{1}$ hybrid metal orbital that will interact with one component of the $e^{\prime \prime}$ cyclopropenium set. The low-lying filled e set of the metal will only have a small interaction with the $\mathrm{e}^{\prime \prime}$ of the ring. The metal-ring interaction that contains only one $\sigma$ molecular orbital will be strengthened if the fragment slides into an $\eta^{1}$ mode (Figure 8c.3). This type of interaction is consistent with the model $\mathrm{C}$ described in Figure $4 \mathbf{B}$. 
While synthesizing the first $\sigma$-complexes in 1978 (vide supra), Gompper and Bartmann synthesized a neutral intermediate $\left(\eta^{1}\right.$ cyclopropenyl)iron $\left(\mathrm{C}_{3} \mathrm{R}_{3}\right) \mathrm{Fe}(\mathrm{CO})_{2} \mathrm{Cp}$ complex 2 (Figure 7C; Gompper and Bartmann, 1978). This coordination mode is rare and is mostly reported as intermediate compounds in the reaction path to the formation of cyclopropylenium $\sigma$-complexes and will not be further discussed.

To conclude, (1) $\mathrm{d}^{7} \mathrm{ML}_{5}$ complexes interact with $\mathrm{C}_{3} \mathrm{R}_{3}{ }^{+}$ with a single $\sigma$-type orbital, resulting in $\eta^{1}$ coordination for $\left[\left(\mathrm{C}_{3} \mathrm{R}_{3}\right) \mathrm{ML}_{5}\right]$ complexes, $(2) \mathrm{d}^{10} \mathrm{ML}_{2}$ complexes have one $\sigma$ and one $\pi$ orbital interaction with $\mathrm{C}_{3} \mathrm{R}_{3}{ }^{+}$, supporting a $\eta^{2}$ bonding mode in complexes with the formula $\left[\left(\mathrm{C}_{3} \mathrm{R}_{3}\right) \mathrm{ML}_{2}\right]^{+}$, and $(3) \mathrm{d}^{9}$ $\mathrm{ML}_{3}$, and isolobal fragments (vide supra) have one $\sigma$ and two $\pi$ orbital interactions with the $\mathrm{C}_{3} \mathrm{R}_{3}^{+}$, resulting in an $\eta^{3}$ mode of coordination in complexes with the formula $\left[\left(\mathrm{C}_{3} \mathrm{R}_{3}\right) \mathrm{ML}_{3}\right]$.

\section{Arylenium Cations}

Carbocations with conjugated $\pi$ systems are one of the most common types of carbocation encountered in organic reactions, and iron was one of the earliest metals used to stabilize these carbocations (Olah et al., 2009). In general, the $\pi$ orbitals of the carbocation can accept the backdonation of filled d orbitals on the metal atom, so the carbocations act as $\mathrm{LX}^{\prime}$ ligands. Figure 9B shows several representative carbocations with $\pi$ allylic systems complexed to an iron (17 and 18) in addition to $\pi$-allylic systems complexed to platinum (19), chromium, molybdenum, or tungsten (20) and an arenium cation stabilized by Os complexation 21 (Green et al., 1977; Mayr et al., 1993; Winemiller et al., 1997). All of these complexes are consistent with the orbital models in Figure 9A.

In addition, these metal-stabilized arylenium cations can be easily characterized by their ${ }^{13} \mathrm{C}$ NMR spectra. For example, complex 19 is featured with a typical resonance around 112 ppm for the central carbon of the $\eta^{3}-C_{3}$ system, along with two terminal carbon atoms of the allyl group around $82 \mathrm{ppm}$ (Green et al., 1977). The osmium $\pi$-complex 21 was also characterized with three ${ }^{13} \mathrm{C}$ resonances in the range of $75-85$ $\mathrm{ppm}$, indicating that the metal binds to the arenium system in an $\eta^{3}$ fashion (Winemiller et al., 1997). Interestingly, studies showed that order of average reactivity of $\mathbf{2 0}$ toward nucleophiles was 20a $>$ 20b $>$ 20c (Mayr et al., 1993), which can be rationalized with the orbital model in Figure 9A. Increasing the atomic radius leads to stronger backdonation of filled $\mathrm{d}$ orbitals on the metal atom $(\mathrm{W}>\mathrm{Mo}>\mathrm{Cr}$ ) resulting in a metal $\pi$ complex that is more stable and less reactive.

\section{Carbocations $\alpha$ to Cyclic $\pi$-Systems}

Another extensively studied carbocation-metal complex is $\alpha$ metallocenylmethylium cation (Hill and Richards, 1961; Davis et al., 1971; Gleiter et al., 2007; Bleiholder et al., 2009; Minić et al., 2015, 2017; Espinosa Ferao and García, 2017; Muratov et al., 2017; Preethalayam et al., 2017; Fomin et al., 2018). Two different resonance structures have been proposed: (1) the cation acts as an L-type ligand by donating its filled $\mathrm{p}$ orbital electron density to the metal center, and (2) the cation acts as an $\mathrm{LX}^{+}$ligand by donating its filled $\mathrm{p}$ orbital electron density to the metal center through carbenium backdonation (Figure 10A). Consequently, some bending of the $s p^{2}$-hybridized carbocationic center toward the metal atom has always been observed, which indicates the formation of double bond.

\section{Carbenium $\alpha$ to Cyclopentadienyl}

$\alpha$-ferrocenyl carbenium ions were first observed by Richards and Hill (1959) through solvolysis of the corresponding ferrocenyl carbinyl acetate (Richards and Hill, 1959). Since then, a wide range of $\alpha$-ferrocenyl carbenium ions have been synthesized and characterized under acidic conditions through their corresponding precusors (Figure 10B). Figure 10B shows some examples of reported $\alpha$-ferrocenyl carbenium ions, such as tetrafluoroborates of ferrocenyl diphenyl cyclopropenium ion 24 (Sime and Sime, 1974), $\alpha, \alpha^{\prime}$-diferrocenyl methylium ion 25 (Cais et al., 1978), ferrocene-annelated allylium ion 26 (Lukasser et al., 1995), and ferrocenyl diphenyl methylium ion 27 (Behrens, 1979), along with their geometric parameters as derived from X-ray diffraction studies. There is consistent bending of the C6 atom of the fulvene ring toward the iron atom in all of these complexes, but the bending angle $(\alpha)$ and Fe-C6 distance (d) vary considerably.

In 24, the positive charge of the carbenium center is delocalized into the cyclopropenylium ring, which results in a bending angle of $6.8^{\circ}$ with an Fe-C6 bond length of $2.96 \AA$. In 25-27, an increase of the angle $(\alpha)$ and a reduction of the FeC6 distance (d) is observed. These geometric changes can be rationalized by the orbital model in Figure 10A. The $\pi$ acidity of the C6 center depends on the identity of $\mathrm{R}^{1}$ and $\mathrm{R}^{2}$. Greater electron density in the carbenium center results in less $\pi$ acidity, which results in weaker $\pi$ backdonation and a conformation like 23b with a smaller bending angle. For example, the $\pi$ systems in $\mathbf{2 4}$ and $\mathbf{2 6}$ increase the electron density of their C6 centers, yielding smaller bending angles.

$\left[\left(\eta^{6}-\mathrm{C}_{5} \mathrm{H}_{4} \mathrm{C}\left(\mathrm{C}_{6} \mathrm{H}_{5}\right)_{2}\right)\right] \mathrm{Cr}\left(\mathrm{CO}_{3}\right)(\mathbf{2 8 b})$ was the first $\eta^{6}$-fulvene complex studied by $\mathrm{X}$-ray analysis (Figure 11A). This data experimentally confirmed the predicted tendency toward strong bending of C6 (Andrianov et al., 1975). The neutral complex 28b shows a bending angle of $28.4^{\circ}$ with a Cr-C6 bond length of $2.55 \AA$, which can be explained by the HOMO obtained from extended Hückel calculations is shown in Figure 11D (Albright et al., 1978). The bending of C6 causes a bonding interaction between C6 and the Cr-centered $\mathrm{e}_{\mathrm{s}}$ orbital (Albright et al., 1978). X-ray studies of various fulvene- $\mathrm{Cr}(\mathrm{CO})_{3}$ complexes with different substituent groups at C6 (28a-e, Figure 11A) showed the strongest bending in the unsubstituted fulvene ligand (28a) and only a small amount of tilt angle for $28 \mathrm{e}$, which contains a conjugated $6 \pi$-electron system at the $\mathrm{C} 6$ atom of the fulvene ligand (Behrens, 1979; Lubke et al., 1983). Fulvene-Cr(CO) 3 complexes with different groups at $\mathrm{C} 6$ also showed an impact on the CO chemical shift of ${ }^{13} \mathrm{C}$ NMR and stretching frequencies by IR (Lubke et al., 1983). The bending angle and C6-Cr distance changes are consistent with the above $\alpha$-ferrocenylmethylium ions. In general, electron-donating groups increase the electron density of the C6 center, thereby increasing $\sigma$-donation and decreasing carbenium backdonation, resulting in smaller tilt angle $(\alpha)$, larger CO chemical shift $(\delta)$ and lower $v_{(\mathrm{CO})}$. 
A<smiles>C=C(C)C=CC(=O)OC(C)C</smiles>

17<smiles>C1=CC2CC1[C@H]1C=C[C@H]21</smiles>

18<smiles>C[C+](Br)Br</smiles>

19<smiles>O=[N+]([O-])[Ge]1C=CC=CC=C1</smiles>

20a: $\mathrm{Cr}$

20b: Mo<smiles>[NH3+]OC1=CC=CCC1</smiles>

21

B<smiles>[R2]C(=[W])C=[W]</smiles>

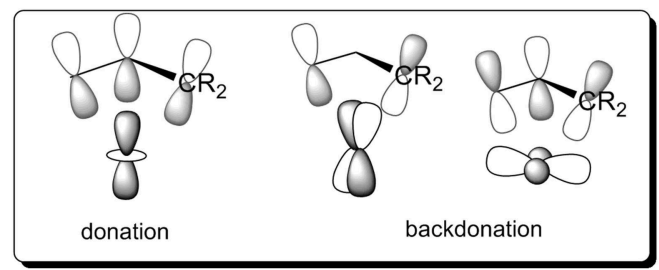

FIGURE 9 | (A) Selective transition metal-stabilized carbocations with conjugated $\phi$-system, and (B) the correlating orbital model

A

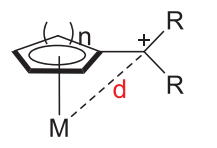

L

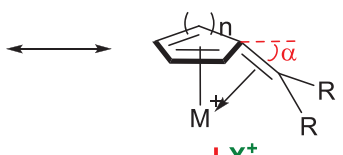

$\mathrm{LX}^{+}$

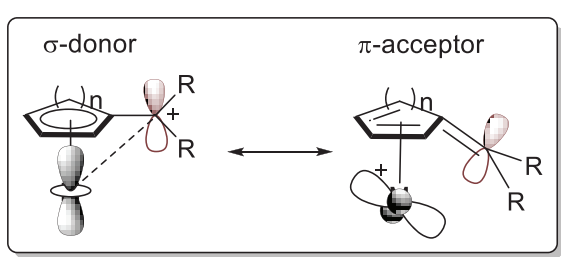

B

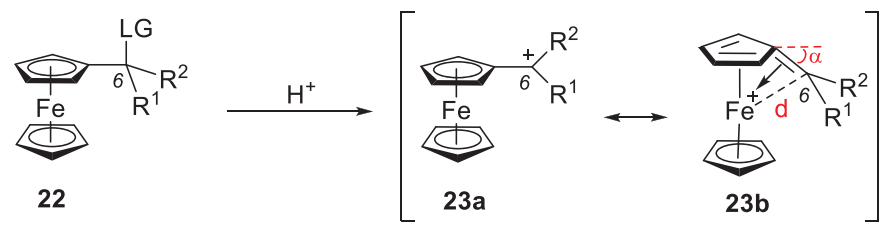

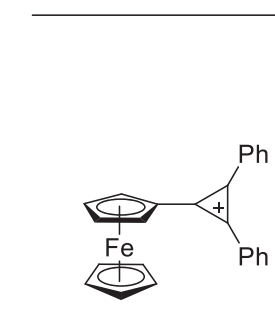

24

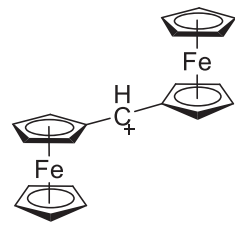

25

$\alpha\left({ }^{\circ}\right)$

6.8

d $(\AA)$

2.957

24.0

12.8

2.686

2.869

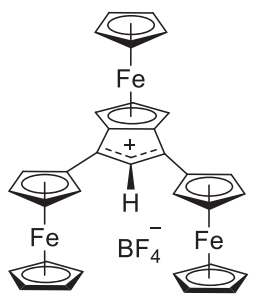

26

$\begin{array}{ll}4.8 & 9.8 \\ 15.7 & 0.08 \\ 3.038 & 2.953 \\ 2.831 & 3.114\end{array}$

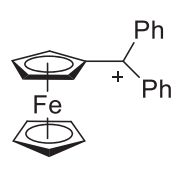

27

21.1

2.715

FIGURE 10 | (A) Two resonance forms of $\alpha$-metallocenylmethylium cation and their orbitals. (B) Selected $\alpha$-metallocenylmethylium cations and their general approach.

X-ray studies also showed that $\alpha$-metallocenyl methylium cations show an increased metal-fulvene interaction with an increase in the metal's molecular mass. The bending angles for complexes 29a (Kreindlin et al., 2000), 29b (Kreindlin et al., 1987), and 29c (Rybinskaya et al., 1989) are $22.7^{\circ}, 38.2^{\circ}$, and $40.8^{\circ}$, respectively, (Figure 11B), which indicates a dramatic increase in metal-fulvene interactions. This is because a larger atomic radius leads to more overlap of filled metal d orbitals with the carbenium $\mathrm{p}$ orbital, resulting in strong carbenium backdonation and a large tilt angle (Figure 10A).

The effect of ligands has also been studied with DFT calculations (Figure 11D; Gleiter et al., 2007). We can see from MO diagrams that electron-rich ligands favor interactions with metal and carbenium centers [Figure 11C, Cp (30) > benzene (31) > CO (32)]. According to the orbital model, the electron-rich ligand can increase the electron density on the 


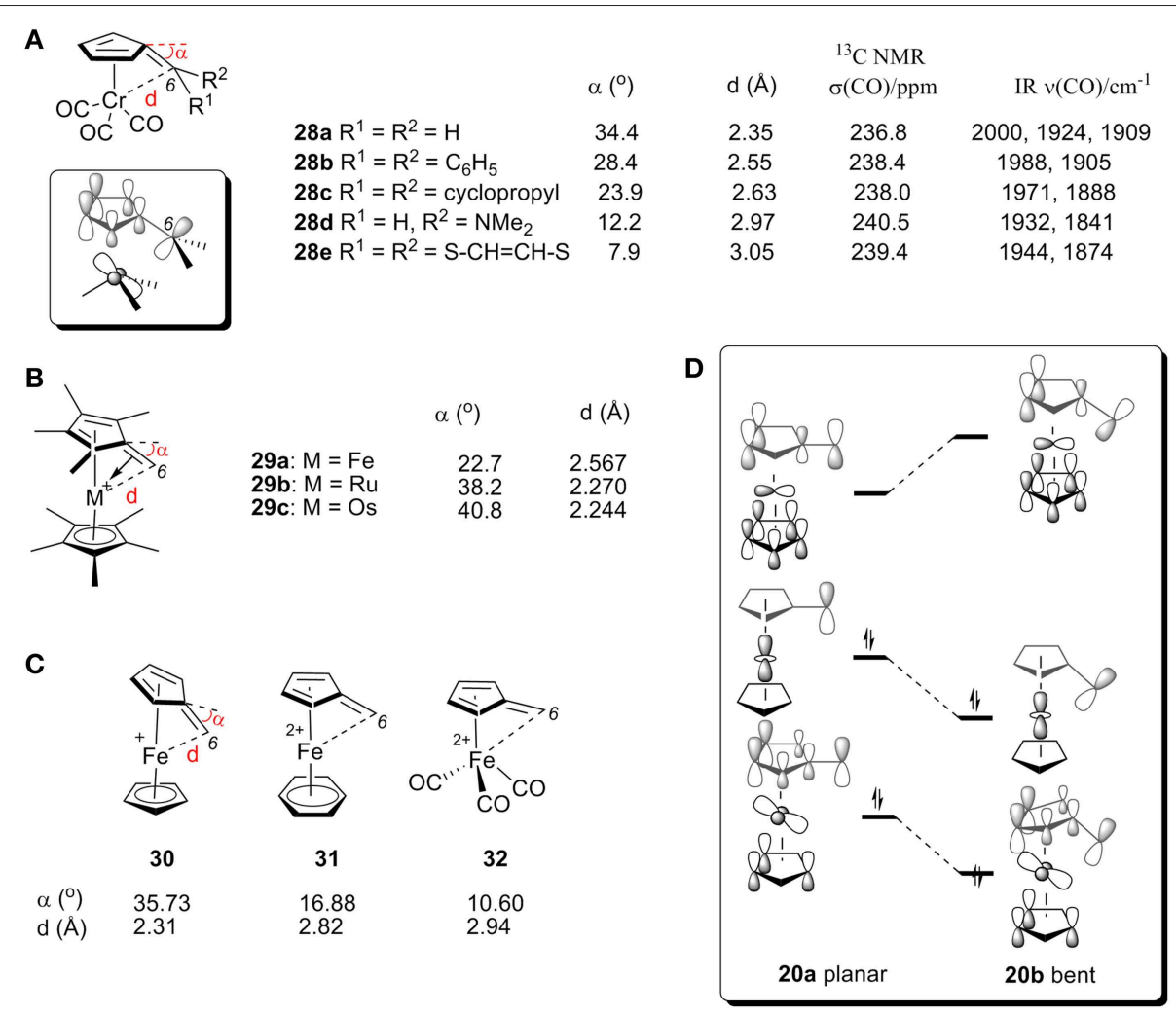

FIGURE 11 | (A) X-ray, ${ }^{13} \mathrm{C}$ NMR, and IR data for CO of complexes 28. (B) Geometric parameters of complex 29 by X-ray analysis. (C) Geometric parameters of complexes 30-32 by DFT calculations. (D) Diagram between the frontier orbitals of a planar and bent $\alpha$-ferrocenyl methylium ion.

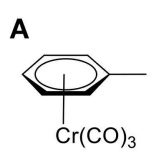

33

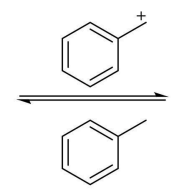

$\triangle E=-12.0 \mathrm{kcal} / \mathrm{mol}$

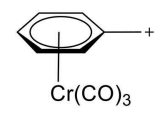

34

B

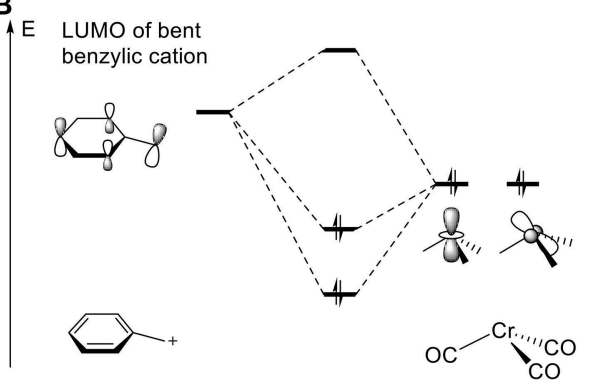

C

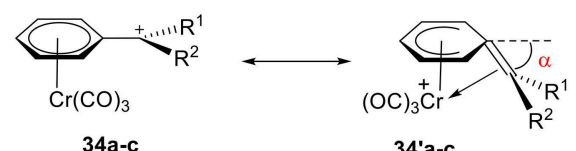

34a-c

a: $R^{1}=R^{2}=H, \alpha=35.3^{\circ}$

b: $\mathrm{R}^{1}=\mathrm{H}, \mathrm{R}^{2}=\mathrm{CH}_{3}, \alpha=21.8^{\circ}$

c: $R^{1}=R^{2}=\mathrm{CH}_{3}, \alpha=12.7^{\circ}$

D

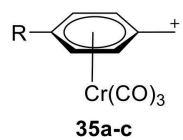

a: $\mathrm{R}=\mathrm{OMe}, \quad \mathrm{pK}_{\mathrm{R}}{ }^{+}=-10.2($ free $=-14.1)$

b: $\mathrm{R}=\mathrm{H}, \quad \mathrm{pK}_{\mathrm{R}}{ }^{+}=-11.8($ free $=-23.8)$

c: $\mathrm{R}=\mathrm{Cl}, \quad \mathrm{pK}_{\mathrm{R}}{ }^{+}=-12.8($ free $=-26.3)$

FIGURE 12 | (A) Chromium-stabilized carbocations. (B) Selected stabilizing orbital interactions between $\mathrm{Cr}(\mathrm{CO})_{3}$ and benzylic cation. (C) Two resonance forms of Chromium-stabilized benzylic cations according to DFT calculation. (D) $\mathrm{pK}_{\mathrm{R}}{ }^{+}$values of different Cr-stabilized benzylic cations.

metal atom, resulting in carbenium backdonation and a large tilt angle.

Figure 11D shows the correlated frontier orbitals of a planar (left) and a bent structure (right) of $\alpha$-ferrocenyl methylium ion (Gleiter et al., 2007; Bleiholder et al., 2009). When the bending angle increases, the LUMO is destabilized and the HOMO is stabilized, which can be rationalized by the increased bonding interaction between the C6 p orbital and the metal d-orbital of the $\mathrm{HOMO}$ and an increased antibonding interaction between the C6 and metal orbitals of the LUMO. As a result, electron density is transferred into an antibonding orbital between $\mathrm{C} 1$ and C6, resulting in a larger bending angle $(\alpha)$. Additionally, increasing 

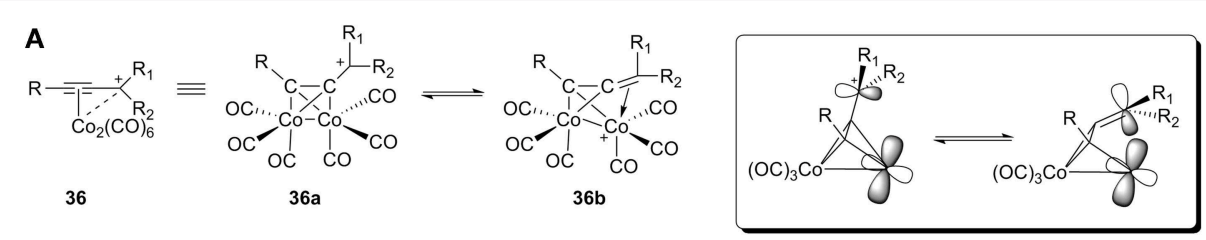

B
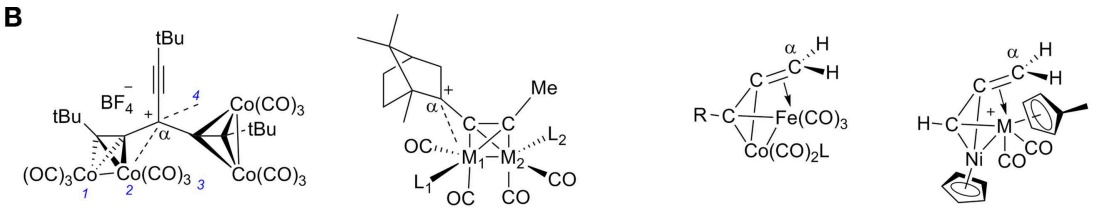

37

38: $M_{1}=M_{2}=C o, L_{1}=L_{2}=C O$

39: $M_{1}=M o, L_{1}=C p$, and $M_{2}=C o, L_{2}=C O$

40: $M_{1}=M_{2}=M o, L_{1}=L_{2}=C O$

\section{1: $\mathrm{R}=\mathrm{H}, \mathrm{L}=\mathrm{CO}$}

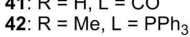

43: $M=M o$
44: $M=W$

FIGURE 13 | (A) Two resonance forms of $\alpha$-metallocenylmethylium cation and their orbitals. (B) Selected representative cationic bimetallic propargyl complexes.

the electron density of the metal center (e.g., heavier metal or electron-rich ligand) or decreasing the electron density of the carbenium center (e.g., electron-withdrawing group) will favor these interactions, leading to larger bending angle $\alpha$.

\section{Carbenium $\alpha$ to Aryl}

$\mathrm{Cr}$ is well-established in its ability to stabilize carbocations, including benzylic, phenonium, and benzonorbornenyl cations (Tantillo et al., 2000; Merlic et al., 2001b; Konietzny et al., 2010; Davis et al., 2013). In 1999, the groups of Houk (Merlic et al., 1999) and Koch (Pfletschinger et al., 1999) pioneered the field through theoretical computations determining the stabilization of benzylic cations by chromium tricarbonyl. As shown in Figure 12A, the homodesmotic equation gives a $\Delta E$ of -12.0 $\mathrm{kcal} / \mathrm{mol}$, suggesting effective stabilization of the benzylic cation 34 by $\mathrm{Cr}(\mathrm{CO})_{3}$ (Figure 12A). This stability is attributed to the other resonance form $34^{\prime}$, in which the benzylic carbon bends down to coordinate to the $\mathrm{Cr}$ atom with an angle of $35.3^{\circ}$, $21.8^{\circ}$, and $12.7^{\circ}$, according to DFT calculations, for methyl, ethyl, and isopropyl cation, respectively, (Figure 12C; Merlic et al., 2001a). This is consistent with the substituent effects observed in Figure 11A. Electron-donating groups result in a smaller tilt angle $(\alpha)$, though steric repulsions are also likely contributive. The stability can also be rationalized in terms of orbital interactions between the hybrid fragment orbitals (Albright, 1982) of $\mathrm{Cr}(\mathrm{CO})_{3}$ and the $\pi$ molecular orbitals of benzylic cation (Figure 12B; Merlic et al., 2001a). In the case of the cation, the low-lying LUMO interacts strongly with the symmetric occupied hybrid metal orbitals. The overlap between the $\mathrm{Cr}$ and benzylic cation orbitals (especially the $\mathrm{d}_{\mathrm{z}}^{2}$-like metal orbital) is increased in two ways: (1) the distortion of the benzylic cation from planarity and, (2) shifting the chromium away from the center of the ring. Electron-donating groups can increase the electron density of $\mathrm{C}_{\alpha}$ center and decrease carbenium backdonation, leading to a smaller tilt angle $(\alpha)$. These computed results are supported by the experimental $\mathrm{pK}_{\mathrm{R}}^{+}$ values of Cr-stabilized benzyl complexes 35a-c (Figure 12D). The $\mathrm{pK}_{\mathrm{R}}^{+}$increased sharply as compared to the corresponding free carbocations, indicating the stabilization of the carbocation by the $\mathrm{Cr}$ atom (Figure 12D). Additionally, more electron-deficient benzyl moieties (electron withdrawing groups) gain an even greater stabilization effect through increased $\pi$-backdonation (Trahanovsky and Wells, 1969; Cheng et al., 1993).

\section{Carbocations $\alpha$ to Acyclic $\pi$-Systems (alkynyl)}

Cobalt, especially cationic dicobalt propargyl complexes, have played a significant role in organic synthesis since their discovery (Nicholas and Pettit, 1971; Nicholas, 1987; McGlinchey et al., 1995; El Amouri and Gruselle, 1996; Amouri et al., 2000). In general, there are two resonance forms for this kind of propargyl cation complex 36: (1) the cation acts as an L-type ligand by donating its filled $\pi$ orbital electron density to the metal center, and (2) the cation acts as a $\mathrm{LX}^{+}$ligand by donating its filled $\pi$ orbital electron density to the metal center with carbenium backdonation (Figure 13A). Both of these resonance forms provide stability to the carbocation.

A wide range of cationic dicobalt propargyl complexes or similar heterobimetallic complexes have been synthesized and characterized (37-44, Figure 13B; Gruselle et al., 1993; Osella et al., 1993; Melikyan et al., 1998; Chetcuti and McDonald, 2002). The propargyl cation always preferentially coordinates to one of the metal atoms in each cluster due to accumulation of positive charge. In studies of these heterobimetallic complexes, the propargyl cation prefers to coordinate to Mo and Fe instead of Co (39, 41, and 42) (Gruselle et al., 1993; Osella et al., 1993) as well as Mo and W instead of Ni (43 and 44) (Chetcuti and McDonald, 2002).

\section{X-Ray Crystallography}

Table 2 gives a summary of the $\mathrm{M}-\mathrm{C}_{\alpha}$ distance of the bimetallic complexes discussed above. In 37, the distances between the carbocationic center and the cobalt atom are 3.07, 2.81, 3.27, and $2.89 \AA$, respectively, for $\mathrm{Co} 1, \mathrm{Co} 2, \mathrm{Co} 3$, and $\mathrm{Co} 4$. The 2-bornyl cation leans toward the Mo atom and the $\mathrm{Mo}-\mathrm{C}_{\alpha}$ distance is $2.74 \AA$ for 39 and $2.91 \AA$ for 40. The preferential stabilization of the 2-bornyl cation by the molybdenum has also been rationalized with molecular orbital calculations at the 
TABLE 2 | X-ray, IR, and ${ }^{13} \mathrm{C}$ NMR data for the complexes.

\begin{tabular}{|c|c|c|c|c|}
\hline Complex & $\begin{array}{c}\text { M-C } \mathbf{C}_{\alpha} \text { distances } \\
\text { (A) }\end{array}$ & IR $v_{\mathrm{CO}}\left(\mathrm{cm}^{-1}\right)$ in DCM & IR $v_{\text {Co }}\left(\mathrm{cm}^{-1}\right)$ in Hexane & ${ }^{13} \mathrm{C}$ NMR $\delta(\mathrm{CO}), \mathrm{ppm}$ \\
\hline 37 & $\begin{array}{l}\text { Co1: } 3.07 \\
\text { Co2: } 2.81 \\
\text { Co3: } 3.27 \\
\text { Co4: } 2.89\end{array}$ & - & - & $194.4,192.2$ \\
\hline 38 & - & - & - & $194.4,192.2$ \\
\hline 39 & 2.74 & - & - & - \\
\hline 40 & 2.91 & - & - & $227.1,226.5,223.0,220.0$ \\
\hline 41 & - & - & $\begin{array}{l}2,084 \mathrm{~m}, 2,041 \text { vs. } 2022 \mathrm{~s} \\
2,014 \mathrm{~m}, 1,993 \mathrm{~m}, 1,981 \mathrm{~m}\end{array}$ & 210.3, $\mathrm{Fe}(\mathrm{CO})_{3} ; 203.0, \mathrm{Co}(\mathrm{CO})_{3}$ \\
\hline 42 & 2.20 & - & 2,052 vs. 2,003 s, 1,989 vs. $1,968 \mathrm{~m}$ & 211.2, $\mathrm{Fe}(\mathrm{CO})_{3} ; 207.3,205.1, \mathrm{Co}(\mathrm{CO})_{2}$ \\
\hline 43 & - & $2,049 \mathrm{~s}, 2,019 \mathrm{~s}, 1,966 \mathrm{~m}$ & - & - \\
\hline 44 & - & $2,047 \mathrm{~m}, 2,013 \mathrm{~s}, 1,989 \mathrm{w}, 1,966 \mathrm{vw}$ & - & - \\
\hline
\end{tabular}

extended Hückel level (Gruselle et al., 1993). Cations 38-40 do not undergo Wagner-Meerwein rearrangement as a result of their stabilization, which otherwise occurs readily for uncomplexed 2alkynylbornyl cations. For 42, the Fe- $\mathrm{C}_{\alpha}$ distance is $2.195 \AA$. The preferential coordination of $\mathrm{C}_{\alpha}$ with $\mathrm{Fe}$ has been explained by the model cluster 41 by means of extended Hückel molecular orbital calculations (Osella et al., 1993).

\section{IR and ${ }^{13} \mathrm{C}$ NMR Spectroscopy}

Table 2 also gives a summary of the IR and ${ }^{13} \mathrm{C}$ NMR data of the above bimetallic complexes. Generally, the IR $\nu_{\mathrm{CO}}$ stretching frequencies of these cations are shifted to higher values (over $2000 \mathrm{~cm}^{-1}$ ) compared to their corresponding neutral precusors (Osella et al., 1993; Chetcuti and McDonald, 2002). In dicobalt cation 27 , the ${ }^{13} \mathrm{C}$ NMR CO signals appear at approximately $194 \mathrm{ppm}$. Analogously, stabilization of a propargyl cation by a molybdenum center results in a shielding of the molybdenum carbonyl signals from approximately 230-220 ppm in 40 (Gruselle et al., 1993). For 41 and 42, stabilization of a propargyl cation by an iron center shifts the carbonyl resonances to approximately $210 \mathrm{ppm}$, while the cobalt carbonyl resonances are around 203-208 ppm (Osella et al., 1993).

This stabilization can be explained in terms of orbital interactions between the metal's $\mathrm{d}$ orbital and the $\pi$ molecular orbitals of the propargyl cation in Figure 13A (Gruselle et al., 1993; McGlinchey et al., 1995). The overlap between the orbitals of the metal center and of the propargyl cation (especially the $\mathrm{d}_{\mathrm{z}}^{2}$-like metal orbital) is increased by the shorter $\mathrm{M}-\mathrm{C}_{\alpha}$ distance, resulting from the propargyl cation bending toward the metal. The preferential coordination with a heavier metal within the heterobimetallic cations $\mathbf{3 9}, \mathbf{4 0}$, and $\mathbf{4 3}$ is consistent with the reactivities of complex $\mathbf{2 0}$ and the conclusion in Figure 9B. However, in complexes 41-43, the carbocation is bound to the lighter element, Fe. This can be explained by considering the isolobal relationship between $\mathrm{Co}(\mathrm{CO})_{3}{ }^{+}$and $\mathrm{Fe}(\mathrm{CO})_{3}$ (McGlinchey et al., 1995). The neutral Fe can provide more effective overlap of filled metal $d$ orbitals with the carbenium's $\mathrm{p}$ orbital than $\mathrm{Co}^{+}$, which makes the interaction with
Fe more attractive. The coordination of the metal with the cation also induced higher $\mathrm{CO}$ stretching frequencies in IR and larger chemical shifts for $\mathrm{CO}$ in ${ }^{13} \mathrm{C}$ NMR.

\section{CONCLUSION}

We proposed two major bonding modes for the orbital interactions between carbeniums and metal centers in $\sigma$ - and $\pi$-complexes. Most of the reported transition metal-carbocation complexes can fall into one of these two categories. In general, heavier metal atoms have larger radii, which can lead to stronger backdonation of filled $\mathrm{d}$ orbitals on the metal atom and greater stabilization of carbocations. In addition, electron-donating groups on the carbocations can increase the electron density of carbon center, thus increasing $\sigma$-donation while decreasing carbenium backdonation. This results in weaker transition metalcarbocation interactions. On the other hand, an electron-rich ligand can increase the electron density on the metal atom, resulting in carbenium backdonation and greater stabilization. The stabilization of carbocations by the transition metal has been unambiguously demonstrated with higher $\mathrm{pK}_{\mathrm{R}}{ }^{+}$values in comparison to the corresponding free carbocations.

Transition metal-stabilized carbocations have been observed and characterized throughout the last century, but there is no comprehensive summary of the bonding modes of these transition metal-carbocation complexes. To our surprise, most of this research was conducted and reported before 2000 and little attention has been given to the field during the last decades, even though much remains unknown about their properties, reactivities, and carbocation interactions with other transition metals (e.g., Pd, Rh, Ir, Ni). Because of their considerable synthetic value, it is of great importance to bring these metal-carbocation interactions back to the interest of the scientific community.

\section{AUTHOR CONTRIBUTIONS}

All authors listed have made a substantial, direct and intellectual contribution to the work, and approved it for publication. 


\section{REFERENCES}

Albright, T. A. (1982). Structure adn reactivity in organometallic chemistry. An applied molecular orbital approach. Tetrahedron 38, 1339-1388. doi: $10.1016 / 0040-4020(82) 80217-2$

Albright, T. A., Hoffmann, R., and Hofmann, P. (1978). Cycloheptatriene and fulvene $\mathrm{Cr}(\mathrm{CO})_{3}$ complexes. Chem. Ber. 111, 1591-1602. doi: 10.1002/cber.19781110440

Amgoune, A., and Bourissou, D. (2011). $\sigma$-Acceptor, Z-type ligands for transition metals. Chem. Commun. 47, 859-871. doi: 10.1039/C0CC04109B

Amouri, H., Bégué, J. P., Chennoufi, A., Bonnet-Delpon, D., Gruselle, M., and Malézieux, B. (2000). Cobalt-induced C-N and C-C bond formation via metalstabilized $\alpha-\mathrm{CF}_{3}$ carbenium ion. Org. Lett. 2, 807-809. doi: 10.1021/ol005554l

Amyes, T. L., Richar, J. P., and Novak, M. (1992). Experiments and calculations for determination of the stabilities of benzyl, benzhydryl, and fluorenyl carbocations: antiaromaticity revisited. J. Am. Chem. Soc. 114, 8032-8041. doi: $10.1021 /$ ja00047a010

Andrianov, V. G., Struchkov, Y. T., Setkina, V. N., Zdanovich, V. I., Zhakaeva, A. Z., and Kursanov, D. N. (1975). X-ray molecular structure of tricarbonyl-( 1-5, $\alpha-\eta$-diphenylfulvene) chrornium, $\left[\left(\eta-\mathrm{C}_{5} \mathrm{H}_{4} \mathrm{CPh}_{2}\right) \mathrm{Cr}(\mathrm{CO})_{3}\right]$. Chem. Commun. 117-118. doi: 10.1039/C39750000117

Bandar, J., and Lambert, T. (2013). Aminocyclopropenium ions: synthesis, properties, and applications. Synth. 45, 2485-2498. doi: $10.1055 / \mathrm{s}-0033-1338516$

Behrens, U. (1979). Übergangsmetall-fulven-komplexe : XIV. Kristallund Molekülstruktur von ferrocenyldiphenylcarbenium-tetrafluoroborat, $\left[\mathrm{Cn}_{5} \mathrm{H}_{5} \mathrm{FeC}_{5} \mathrm{H}_{4} \mathrm{C}\left(\mathrm{C}_{6} \mathrm{H}_{5}\right)_{2}\right]^{+} \mathrm{BF}_{4}^{-}$. Ein Fulven-eisen-komplex? J. Organomet. Chem. 182, 89-98. doi: 10.1016/S0022-328X(00)85878-7

Benitez, D., Shapiro, N. D., Tkatchouk, E., Wang, Y., Goddard, W. A., and Toste, F. D. (2009). A bonding model for gold(i) carbene complexes. Nat. Chem. 1, 482-486. doi: 10.1038/nchem.331

Bleiholder, C., Rominger, F., and Gleiter, R. (2009). $\alpha$-metallocenylmethylium ions and their isoelectronic congeners: a comparison based on DFT calculations. Organometallics 28, 1014-1017. doi: 10.1021/om800573u

Bouhadir, G., and Bourissou, D. (2016). Complexes of ambiphilic ligands: reactivity and catalytic applications. Chem. Soc. Rev. 45, 1065-1079. doi: 10.1039/C5CS00697J

Braunschweig, H., and Dewhurst, R. D. (2011). Transition metals as Lewis bases: "Z-type" boron ligands and metal-to-boron dative bonding. Dalt. Trans. 40, 549-558. doi: 10.1039/C0DT01181A

Breslow, R. (1957). Synthesis of the $\sigma$-triphenylcy clopropenyl cation. J. Am. Chem. Soc. 79, 5318-5319. doi: 10.1021/ja01576a067

Breslow, R., and Chang, H. W. (1961). Triarylcyclopropenium ions. Synthesis and stability in the phenyl p-anisyl series. J. Am. Chem. Soc. 83, 2367-2375. doi: 10.1021/ja01471a031

Brown, T. J., Weber, D., Gagn,é, M. R., and Widenhoefer, R. A. (2012). Mechanistic analysis of gold(I)-catalyzed intramolecular allene hydroalkoxylation reveals an off-cycle bis(gold) vinyl species and reversible C-O bond formation. J. Am. Chem. Soc. 134, 9134-9137. doi: 10.1021/ja303844h

Cais, M., Dani, S., Herbstein, F., and Kapon, M. (1978). Determination of the crystal structure of $\alpha, \alpha$-diferrocenylmethylium tetrafluoroborate, a stable carbenium ion salt, and a comparison of its structure with those of other organometallic carbenium cations. J. Am. Chem. Soc. 100, 5554-5558. doi: $10.1021 / \mathrm{ja} 00485 \mathrm{a} 047$

Cheng, J. P., Handoo, K. L., and Parker, V. D. (1993). Hydride affinities of carbenium ions in acetonitrile and dimethyl sulfoxide solution. J. Am. Chem. Soc. 115, 2655-2660. doi: 10.1021/ja00060a014

Chetcuti, M. J., and McDonald, S. R. (2002). Propargylic cations stabilized on nickel-molybdenum and nickel-tungsten bonds. Organometallics 21, 3162-3168. doi: 10.1021/om020155a

Chiang, T., Kerber, R. C., Kimball, S. D., and Lauher, J. W. (1979). $\left(\eta^{3}-\right.$ Triphenylcyclopropenyl) tricarbonylcobalt. Inorg. Chem. 18, 1687-1691. doi: 10.1021/ic50196a058

Churchill, M. R., Fettinger, J. C., McCullough, L. G., and Schrock, R. R. (1984). Transformation of a tungstenacyclobutadiene complex into a nonfluxional $\eta^{3}$ cyclopropenyl complex by addition of a donor ligand. The X-ray structure of $\mathrm{W}\left(\eta^{5}-\mathrm{C}_{5} \mathrm{H}_{5}\right)\left[\mathrm{C}_{3}\left(\mathrm{CMe}_{3}\right)_{2} \mathrm{Me}\right]\left(\mathrm{PMe}_{3}\right) \mathrm{Cl}_{2}$. J. Am. Chem. Soc. 106, 3356-3357. doi: 10.1021/ja00323a051
Ciabattoni, J., and Nathan, E. C. (1969). Di-t-butylcyclopropenone and substituted Di-t-butylcyclopropenyl Cations. J. Am. Chem. Soc. 91, 4766-4771. doi: $10.1021 /$ ja01045a031

Davis, R. E., Simpson, H. D., Gnce, N., and Pettit, R. (1971). The structure of $\alpha$-cyclobutadienyliron tricarbonyl carbonium ions. J. Am. Chem. Soc. 93, 6688-6690. doi: 10.1021/ja00753a068

Davis, R. L., Lodewyk, M. W., Siebert, M. R., and Tantillo, D. J. (2013). Complex consequences: substituent effects on metala.. arylmethylium interactions. J. Organomet. Chem. 748, 68-74. doi: 10.1016/j.jorganchem.2013. 02.034

Deno, N. C., Jaruzelski, J. J., and Schriesheim, A. (1955). Carbonium ions. I. an acidity function $\left(\mathrm{C}_{0}\right)$ derived from arylcarbonium ion equilibria. J. Am. Chem. Soc. 77, 3044-3051. doi: 10.1021/ja01616a036

Ditchfield, R., Hughes, R. P., Tucker, D. S., Bierwagen, E. P., Robbins, J., Robinson, D. J., et al. (1993). Synthesis and dynamic NMR studies of $\eta^{3}$-triphenyl- and $\eta^{3}$ trimethylcyclopropenyl complexes of ruthenium, $\left[\mathrm{Ru}\left(\eta^{5}-\mathrm{C}_{5} \mathrm{R}_{5}\right)\left(\eta^{3}-\mathrm{C}_{3} \mathrm{R}_{3}^{\prime}\right) \mathrm{X}_{2}\right]$ $\left(\mathrm{R}=\mathrm{H}, \mathrm{Me} ; \mathrm{R}^{\prime}=\mathrm{Me}, \mathrm{Ph} ; \mathrm{X}=\mathrm{Cl}, \mathrm{Br}, \mathrm{I}\right)$. Extended Hückel molecular orbital study of barriers to rotation of $\eta^{3}$-cyclopropenyl. Organometallics 12, 2258-2267. doi: 10.1021/om00030a041

Donaldson, W. A., and Hughes, R. P. (1982). Mechanism of formation of $\left(\eta^{3}-\right.$ oxocyclobutenyl)cobalt compounds from $\left[\mathrm{Co}(\mathrm{CO})_{4}\right]$ - and cyclopropenium cations. J. Am. Chem. Soc. 104, 4846-4859. doi: 10.1021/ja00382a019

Drew, M. G. B., Brisdon, B. J., and Day, A. (1981). Cyclopropenyl and oxocyclobutenyl complexes of molybdenum. Crys- tal and molecular structures of (2,2'-bipyridine)bromodicarbonyl(1-3- $\eta-1$ ,2,3-triphenylcyclopropenyl)molybdenum( II) and (2,2'-bipyridine)bromodicarbonyl(2-4- $\eta-1$-oxo-2,3,4-triphenylcyclobutenyl)molybenum(II). J. Chem. Soc., Dalt. Trans. 1310-1316. doi: 10.1039/DT9810001310

Echavarren, A. M., and Nevado, C. (2004). Non-stabilized transition metal carbenes as intermediates in intramolecular reactions of alkynes with alkenes. Chem. Soc. Rev. 33, 431-436. doi: 10.1039/b308768a

El Amouri, H., and Gruselle, M. (1996). New bonding modes, fluxional behavior, and reactivity in dinuclear complexes bridged by four-electron donor unsaturated hydrocarbons. Chem. Rev. 96, 1077-1104. doi: 10.1021/cr9500040

Ellis, J. E. (2003). Metal carbonyl anions: from $\left[\mathrm{Fe}(\mathrm{CO})_{4}\right]_{2}$-to $\left[\mathrm{Hf}(\mathrm{CO})_{6}\right]_{2}$-and beyond. Organometallics 22, 3322-3338. doi: 10.1021/om0301051

Espinosa Ferao, A., and García, R. (2017). Fulvenization as characteristic geometric distortion in electron deficient ferrocenes. Tetrahedron 73, 952-956. doi: 10.1016/j.tet.2017.01.019

Fischer, E. O. (1976). On the way to carbene and carbyne complexes. Adv. Organomet. Chem. 14, 1-32. doi: 10.1016/S0065-3055(08)60647-4

Fomin, V. M., Kochetkova, K. S., and Klyuchevskii, K. V. (2018). Redox isomerism of $\alpha$-ferrocenylcarbenium ions. Russ. J. Gen. Chem. 88, 948-953. doi: $10.1134 / S 1070363218050183$

Frenking, G. (2002). "The dewar-chatt-duncanson bonding model of transition metal-olefin complexes examined by modern quantum chemical methods," in Modern Coordination Chemistry: The Legacy of Joseph Chatt (Royal Society of Chemistry). doi: 10.1039/9781847551481-00111

Fürstner, A., and Davies, P. W. (2007). Catalytic carbophilic activation: catalysis by platinum and gold $\pi$ acids. Angew. Chem. Int. Ed. 46, doi: 10.1002/anie.200604335

Gade, L. H., Memmler, H., Kauper, U., Schneider, A., Fabre, S., Bezougli, I., et al. (2000). Cooperative reactivity of early-late heterodinuclear transition metal complexes with polar organic substrates. Chem. Eur. J. 6, 692-708. doi: 10.1002/ (SICI)1521-3765(20000218)6:4\&lt;692::AID-CHEM692\&gt;3.0.CO;2-2

Ghilardi, C. A., Innocenti, P., Midollini, S., Orlandini, A., and Vaccab, A. (1995). Dynamic nuclear magnetic resonance studies of the $\eta^{3}$-triphenylcyclopropenyl complexes $\left[\mathrm{M}\left(\eta^{3}-\mathrm{C}_{3} \mathrm{Ph}_{3}\right) \mathrm{L}\right] \mathrm{PF}_{6}\left[\mathrm{M}=\mathrm{Ni}\right.$, Pd or Pt; $\left.\mathrm{L}=\mathrm{MeC}\left(\mathrm{CH}_{2} \mathrm{PPh}_{2}\right)_{3}\right]$. Crystal structure of the platinum derivative. J. Chem. Soc. Dalt. Trans. 1109-1113. doi: 10.1039/DT9950001109

Gleiter, R., Bleiholder, C., and Rominger, F. (2007). $\alpha$-Metallocenylmethylium ions and isoelectronic fulvene complexes of d6 to d9 metals. Structural considerations. Organometallics 26, 4850-4859. doi: 10.1021/om700272j

Gompper, R., and Bartmann, E. (1978). $\sigma$-dicarbonylcyclopentadienyliron derivatives of cyclopropenes and cyclopropenylium salts. Angew. Chem. Int. Ed. English 17, 456-457. doi: 10.1002/anie.197804561

Gompper, R., and Bartmann, E. (1985). $\sigma$-cyclopropenyl, dicarbonyl$\eta^{5}$-cyclopentadienyl(1-cyclopropenyl)iron complexes- a new class 
of $\sigma$-cyclopropenyl complexes. Angew. Chem. Int. Ed. 24, 209. doi: 10.1002/anie.198502091

Green, B. M., Grove, D. M., Spencer, J. L., and Stone, F. G. (1977). A. Chemistry of Bis(cyclo-octa-1,5-idene) platinum : reactions with electrophiles. J. Chem. Soc. Dalt. Trans. 2228-2234. doi: 10.1039/dt9770002228

Green, M. L. H. (1995). A new approach to the formal classification of covalent compounds of the elements. J. Organomet. Chem. 500, 127-148. doi: 10.1016/0022-328X(95)00508-N

Gruselle, M., El Hafa, H., Nikolski, M., Jaouen, G., Vaisserman, J. J., Li, L., et al. (1993). Metal cluster stabilized 2-bornyl cations: a synthetic, X-ray crystallographic, and EHMO study. Organometallics 12, 4917-4925. doi: 10.1021/om00036a035

Harris, R. J., and Widenhoefer, R. A. (2016). Gold carbenes, gold-stabilized carbocations, and cationic intermediates relevant to gold-catalysed enyne cycloaddition. Chem. Soc. Rev. 45, 4533-4551. doi: 10.1039/C6CS00171H

Hashmi, A. S. (2014). Dual gold catalysis. Acc. Chem. Res. 47, 864-876. doi: $10.1021 / \operatorname{ar} 500015 \mathrm{k}$

Hashmi, A. S., and Rudolph, M. (2008). Gold catalysis in total synthesis. Chem. Soc. Rev. 37, 1766-1775. doi: 10.1039/b615629k

Hayter, R. G. (1968). A new route to $\pi$-allyl complexes of molybdenum and tungsten. J. Organomet. Chem. 13, 4-6. doi: 10.1016/S0022-328X(00) 88846-4

Hill, E. A., and Richards, J. H. (1961). Carbonium ion stabilization by metallocene nuclei. II. $\alpha$-metallocenylcarbonium ions. J. Am. Chem. Soc. 83, 3840-3846. doi: 10.1021/ja01479a025

Hopkinson, M. N., Tlahuext-Aca, A., and Glorius, F. (2016). Merging visible light photoredox and gold catalysis. Acc. Chem. Res. 49, 2261-2272. doi: 10.1021/acs.accounts.6b00351

Hughes, R. P., Lambert, J. M., and Hubbard, J. L. (1986). Reactions of $\left(\eta^{3}\right.$-Cyclopropenyl)iron Complexes With Tertiary Phosphorus Ligands. Competition between ligand substitution and cyclopropenyl migration to carbon monoxide followed by ring expansion to give oxocyclobutenyl ligands. Organometallics 5, 797-804. doi: 10.1021/om00135a030

Hughes, R. P., Reisch, J. W., and Rheingold, A. L. (1985). Oxidative addition of cyclopropenyl cations to zerovalent molybdenum and tungsten centers. Synthesis of $\eta^{3}$-cyclopropenyl and $\eta^{3}$-oxocyclobutenyl complexes of molybdenum(II) and tungsten(II). crystal and molecular structures of $\left[\mathrm{Mo}\left(\eta^{5}-\mathrm{C}_{5} \mathrm{H}_{5}\right)\left(\eta^{3}-\mathrm{C}_{3} \mathrm{Ph}_{2} \mathrm{R}\right)(\mathrm{CO})_{2}\right]$. Organometallics 4, 1754-1761. doi: $10.1021 / 0 \mathrm{~m} 00129 \mathrm{a} 012$

Hughes, R. P., Tucker, D. S., and Rheingold, A. L. (1993). Preparation and dynamic behavior of $\eta^{3}$-cyclopropenyl complexes of cobalt, rhodium, and iridium. crystal and molecular structure of $\left[\operatorname{Ir}\left(\eta^{3}-\mathrm{C}_{3}^{\mathrm{t}} \mathrm{Bu}_{3}\right)(\mathrm{CO})_{3}\right]$. Organometallics 12 , 3069-3074. doi: 10.1021/om00032a032

Jemmis, E. D., and Hoffmann, R. (1980). Cleaving CC bonds in cyclopropenium ions. J. Am. Chem. Soc. 102, 2570-2575. doi: 10.1021/ja00528a009

Jia, M., and Bandini, M. (2015). Counterion effects in homogeneous gold catalysis. ACS Catal. 5, 1638-1652. doi: 10.1021/cs501902v

Jiang, Y., Freyer, J. L., Cotanda, P., Brucks, S. D., Killops, K. L., Bandar, J. S., et al. (2015). The evolution of cyclopropenium ions into functional polyelectrolytes. Nat. Commun. 6:5950. doi: 10.1038/ncomms6950

Jones, J. S., and Gabbaï, F. P. (2016). Coordination- and redox-noninnocent behavior of ambiphilic ligands containing antimony. Acc. Chem. Res. 49, 857-867. doi: 10.1021/acs.accounts.5b00543

Jorgensen, W. L., and Salem, L. (1973). The Organic Chemist's Book of Orbitals. New York, NY: Academic Press. doi: 10.1016/B978-0-12-390250-4.X5001-2

Komatsu, K., and Kitagawa, T. (2003). Cyclopropenylium cations, cyclopropenones, and heteroanalogues - recent advances. Chem. Rev. 103, 1371-1427. doi: 10.1021/cr010011q

Konietzny, S., Finze, M., and Rei,ß, G. J. (2010). Tricarbonyl-6,6'-dimethylfulvene chromium(0) - structural properties. J. Organomet. Chem. 695, 2089-2092. doi: 10.1016/j.jorganchem.2010.05.017

Konishi, H., Matsumoto, S., Kamitori, Y., Ogoshi, H., and Yoshida, Z.-I. (1978). Synthesis and properties of diaminocyclopropenylidene transition metal complexes. Chem. Lett. 7, 241-244. doi: 10.1246/cl.1978.241

Kozma, Á., Petuškova, J., Lehmann, C. W., and Alcarazo, M. (2013). Synthesis, structure and reactivity of cyclopropenyl-1-ylidene stabilized S(II), $\mathrm{Se}(\mathrm{II})$ and $\mathrm{Te}(\mathrm{II})$ mono- and dications. Chem. Commun. 49, 4145-4147. doi: $10.1039 / \mathrm{C} 2 \mathrm{CC} 36225 \mathrm{~B}$
Kreindlin, A. Z., Dolgushin, F. M., Yanovsky, A. I., Kerzina, Z. A., Petrovskii, P. V., and Rybinskaya, M. I. (2000). Synthesis, crystal and molecular structure of $\left[\left\{\mathrm{C}_{5} \mathrm{Me}_{5} \mathrm{FeC}_{5} \mathrm{Me}_{4} \mathrm{CH}_{2}\right\}^{+} \mathrm{B}\left\{\mathrm{C}_{6} \mathrm{H}_{3}\left(\mathrm{CF}_{3}\right)_{2}\right\}_{4}^{-}\right]$, the first example of a structurally characterized primary ferrocenylcarbocation. J. Organomet. Chem. 616, 106-111. doi: 10.1016/S0022-328X(00)00566-0

Kreindlin, A. Z., Petrovskii, P. V., Rybinskaya, M. I., Yanovskii, A. I., and Struchkov, Y. T. (1987). Synthesis and crystal structure of nonamethylruthenocenylcarbenium hexafluorophosphate. J. Organomet. Chem. 319, 229-237. doi: 10.1016/0022-328X(87)83030-9

Kuchenbeiser, G., Donnadieu, B., and Bertrand, G. (2008). Stable bis(diisopropylamino)cyclopropenylidene (BAC) as ligand for transition metal complexes. J. Organomet. Chem. 693, 899-904. doi: 10.1016/j.jorganchem.2007.11.056

Li, Z., Brouwer, C., and He, C. (2008). Gold-catalyzed organic transformations. Chem. Rev. 108, 3239-3265. doi: 10.1021/cr0684341

Lichtenberger, D. L., Hoppe, M. L., Subramanian, L., Kober, E. M., Hughes, R. P., Hubbard, J. L., et al. (1993). Electron distribution and bonding in $\eta^{3}$-cyclopropenyl-metal complexes. Organometallics 12, 2025-2031. doi: 10.1021/om00030a011

Lubke, B., Edelmann, F., and Behrens, U. (1983). Synthese und Struktur von (Fulven) $\mathrm{Cr}(\mathrm{CO})_{3}$-Komplexen. Chem. Ber. 116, 11-26. doi: 10.1002/cber.19831160104

Lukasser, J., Angleitner, H., Schottenberger, H., Kopacka, H., Schweiger, M., Bildstein, B., et al. (1995). Stable and crystalline allylium and allenylium salts with ferrocenyl substituents. Organometallics 14, 5566-5578. doi: 10.1021/om00012a025

Mann, B. L. (1982). "Comprehensive organometallic chemistry," in Comprehensive Organometallic Chemistry, Vol. 9, eds G. Wilkinson, F. G. A. Stone, and E. W. Abel (Oxford: Pergamon Press), 89.

Martin, D., Melaimi, M., Soleilhavoup, M., and Bertrand, G. (2011). A brief survey of our contribution to stable carbene chemistry. Organometallics 30, 5304-5313. doi: 10.1021/om200650x

Mayr, B. H., Müller, K.-H., and Rau, D. (1993). Comparison of the electrophilicities. Angew. Chem. Int. Ed. 1, 1630-1632. doi: 10.1002/anie.199316301

McClure, M. D., and Weaver, D. L. (1973). An unusual cyclopropenyl complex.

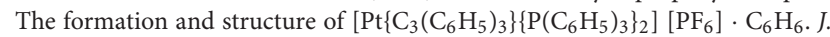
Organomet. Chem. 54, 59-61. doi: 10.1016/S0022-328X(00)84983-9

McGlinchey, M. J., Girard, L., and Ruffolo, R. (1995). Cluster-stabilized cations: synthesis, structures, molecular dynamics and reactivity. Coord. Chem. Rev. 143, 331-381. doi: 10.1016/0010-8545(95)01131-8

Mealli, C., Midollini, S., Moneti, S., and Albright, T. A. (1983). Synthesis and X-ray analysis of a nickel triphenyl-cyclopropenyl complex. A MO-interpretation of the geometry and bonding in the $\left(\mathrm{C}_{3} \mathrm{H}_{3}\right) \mathrm{ML}_{3}$-type of complexes. Helv. Chim. Acta 66, 557-569. doi: 10.1002/hlca.19830660216

Mealli, C., Midollini, S., Moneti, S., and Sacconi, L. (1981). Cationic $\eta 3-$ Triphenylcyclopropenylnickel complexes with tridentate ligands containing $\mathrm{N}$ $\mathrm{P}, \mathrm{As}$ as the donor atoms. Molecular structure of $\eta 3$-triphenylcyclopropenyl1,1,1-tris(diphenylphosphinomethyl)ethanenickel perchlorate. J. Organomet. Chem. 205, 273-279. doi: 10.1016/S0022-328X(00)81484-9

Mealli, C., Midollini, S., Moneti, S., Sacconi, L., Silvestre, J., and Albright, T. A. (1982). Structures of $\left[\left(\mathrm{Ph}_{3} \mathrm{C}_{3}\right) \mathrm{M}\left(\mathrm{PPh}_{3}\right)_{2}\right]^{+} \mathrm{X}^{-}$Complexes. An experimental and theoretical study of ring-whizzing. J. Am. Chem. Soc. 104, 95-107. doi: $10.1021 /$ ja00365a020

Melaimi, M., Soleilhavoup, M., and Bertrand, G. (2010). Stable cyclic carbenes and related species beyond diaminocarbenes. Angew. Chem. Int. Ed. 49, 8810-8849. doi: 10.1002/anie.201000165

Melikyan, G. G., Bright, S., Monroe, T., Hardcastle, K. I., and Ciurash, J. (1998). Overcoming a longstanding challenge: X-ray structure of a $\left[\mathrm{Co}_{2}(\mathrm{CO})_{6}\right]$ complexed propargyl cation. Angew. Chem. Int. Ed. doi: 10.1002/(SICI)15213773(19980202)37:1/2<161::AID-ANIE161>3.0.CO;2-8

Merlic, C. A., Hietbrink, B. N., and Houk, K. N. (2001a). Donor and acceptor properties of the chromium tricarbonyl substituent in benzylic and homobenzylic anions, cations, and radicals. J. Org. Chem. 66, 6738-6744. doi: 10.1021/jo010620y

Merlic, C. A., Miller, M. M., Hietbrink, B. N., and Houk, K. N. (2001b). Reactivity of $\left(\eta^{6}\right.$-arene)tricarbonylchromium complexes toward additions of anions, cations, and radicals. J. Am. Chem. Soc. 123, 4904-4918. doi: 10.1021/ja000600y 
Merlic, C. A., Walsh, J. C., Tantillo, D. J., and Houk, K. N. (1999). Chemical hermaphroditism: the potential of the $\mathrm{Cr}(\mathrm{CO})_{3}$ moiety to stabilize transition states and intermediates with anionic, cationic, or radical character at the benzylic position. J. Am. Chem. Soc. 121, 3596-3606. doi: 10.1021/ja98 $3934 \mathrm{k}$

Miki, S., Ogno, T., Iwasaki, H., and Yoshida, Z. -I. (1988). Syntheses, spectroscopic characterization and electronic structure of cyclopropenylidene ligated platinum complexes. J. Phys. Org. Chem. 1, 333-349. doi: 10.1002/poc.610010604

Mingos, D. M. P. (2001). A historical perspective on Dewar's landmark contribution to organometallic chemistry. J. Organomet. Chem. 635, 1-8. doi: 10.1016/S0022-328X(01)01155-X

Minić, A., Stevaović, D., Damljanović, I., Pejović, A., Vukićević, M., Bogdaonvić, G. A., et al. (2015). Synthesis of ferrocene-containing six-membered cyclic ureas via $\alpha$-ferrocenyl carbocations. RSC Adv. 5, 24915-24919. doi: 10.1039/C5RA01383F

Minić, A., Stevaović, D., Vukićević, M., Bogdaonvić, G. A., D’hooghe, M., Radulović, N. S., et al. (2017). Synthesis of novel 4-ferrocenyl1,2,3,4-tetrahydroquinolines and 4-ferrocenylquinolines via $\alpha$-ferrocenyl carbenium ions as key intermediates. Tetrahedron 73, 6268-6274. doi: $10.1016 /$ j.tet.2017.09.014

Moerdyk, J. P., and Bielawski, C. W. (2013). Stable carbenes. Contemp. Carbene Chem. 40-74. doi: 10.1002/9781118730379.ch2

Mond, L., Gold, L. H., and Schmidbaur, H. (1995). Ludwig mond lecture. High Carat Gold Compounds. Chem. Soc. Rev. 391-400. doi: 10.1039/cs9952400391

Morton, M. S., and Selegue, J. P. (1999). The cyclo-C3ligand: trimetallic cyclopropenium complexes of Group 6-8 metals, including the X-ray crystal structure of $\left[\left\{\mathrm{Fe}(\mathrm{CO})_{2}(\mathrm{Cp})\right\}_{3}\left(\mu_{3}-\mathrm{C}_{3}\right)\right]\left[\mathrm{SbF}_{6}\right]$. J. Organomet. Chem. 578, 133-143. doi: 10.1016/S0022-328X(98)01115-2

Moss, R. A., Shen, S., Krogh-Jespersen, K., Potenza, J. A., Schugar, H. J., and Munjal, R. (1986). Cyclopropyl/phenylcyclopropenyl cations: studies in stabilization. J. Am. Chem. Soc. 108, 134-140. doi: 10.1021/ja00261a022

Muratov, D. V., Romanov, A. S., Corsinni, M., Fabrizi de Biani, F., and Siebert, W. (2017). The first triple-decker complex with a carbenium center, $[\mathrm{CpCo}(\mu-$ $\left.\left.\mathrm{C}_{3} \mathrm{~B}_{2} \mathrm{Me}_{5}\right) \mathrm{RuC}_{5} \mathrm{Me}_{4} \mathrm{CH}_{2}\right]^{+}$: synthesis, reactivity, $\mathrm{X}$-ray structure, and bonding. Chem. Eur. J. 23, 11935-11944. doi: 10.1002/chem.201702571

Nelson, J. H., Wheelock, K. S., Cusachs, L. C., and Jonassen, H. B. (1969). The nature of bonding in zerovalent platinum-acetylene complexes. Chem. Commun. 1019-1020. doi: 10.1039/C29690001019

Nesmeyanov, A. N., Perevalova, E. G., Grandberg, K. I., Lemenovskii, D. A., Baukova, T. V., and Afanassova, O. B. (1974). A new type of organogold compound. J. Organomet. Chem. 65, 131-144. doi: 10.1016/S0022-328X(00)83895-4

Nicholas, K. M. (1987). Chemistry and synthetic utility of cobalt-complexed propargyl cations. Acc. Chem. Res. 20, 207-214. doi: 10.1021/ar00138a001

Nicholas, K. M., and Pettit, P. (1971). An alkyne protecting group. Tetrahedron Lett. 3475-3478. doi: 10.1016/S0040-4039(01)97209-0

Norris, J. F. (1901). On the nonexistence of trivalent carbon. Am. Chem. J $25,117-122$.

Norris, J. F., and Sanders, W. W. (1901). on triphenylchloromethane. Am. Chem. J. $25,54-62$.

Öfele, K. (1970). Dichlor(2,3-diphenylcyclopropenyliden)palladium(II). J. Organomet. Chem. 22, C9-C11. doi: 10.1016/S0022-328X(00)83065-X

Ofele, K., Tosh, E., Taubmann, C., and Herrmann, W. A. (2009). Carbocyclic carbene metal complexes. Chem. Rev. 109, 3408-3444. doi: 10.1021/cr800516g

Olah, G. A. (1972). The general concept and structure of carbocations based on differentiation of trivalent ('classical') carbenium ions from three-center bound penta- or tetracoordinated ('nonclassical') carbonium ions. The role of carbocations in electrophilic reactions. J. A. Chem. Soc. 94, 808-820. doi: $10.1021 /$ ja00758a020

Olah, G. A. (1995). My search for carbocations and their role in chemistry, nobel lecture. Angew. Chem. Int. Ed. 34, 1393-1405. doi: 10.1002/anie.1995 13931

Olah, G. A. (2004). Carbocation Chemistry. Hoboken, NJ: Wiley. doi: 10.1002/9780471678656

Olah, G. A., Prakash, G. K. S., Molnár, Á., and Sommer, J. (eds.). (2009). "Chapter 3: Carbocation in superacid systems," in Superacid Chemistry (John Wiley \& Sons, Inc.), 83-310. doi: 10.1002/9780470421604
Osawa, M., Hoshino, M., and Hashizume, D. (2008). Photoluminescent properties and molecular structures of $\left[\mathrm{NaphAu}\left(\mathrm{PPh}_{3}\right)\right]$ and $\left[\mu-\mathrm{Naph}\left\{\mathrm{Au}\left(\mathrm{PPh}_{3}\right)\right\}_{2}\right] \mathrm{ClO}_{4}$ $($ Naph $=2$-naphthyl). Dalt. Trans. 4, 2248-2252. doi: 10.1039/b714609d

Osella, D., Dutto, G., Jaouen, G., Vessieres, A., Raithby, P. R., De Benedetto, L., et al. (1993). Modification of estradiol at the 17-position. Effect of changing the $\mathrm{OH}$ group for a transition-metal carbonyl cluster on the estradiol receptor recognition. Organometallics 12, 4545-4552. doi: 10.1021/om00035a045

Owen, G. R. (2012). Hydrogen atom storage upon Z-class borane ligand functions: an alternative approach to ligand cooperation. Chem. Soc. Rev. 41, 3535-3546. doi: $10.1039 /$ c2cs15346g

Owen, G. R. (2016). Functional group migrations between boron and metal centres within transition metal-borane and -boryl complexes and cleavage of $\mathrm{H}-\mathrm{H}, \mathrm{E}-$ $\mathrm{H}$ and E-E' bonds. Chem. Commun. 52, 10712-10726. doi: 10.1039/C6CC0 $3817 \mathrm{D}$

Parkin, G. (2007). “Classification of organotransition metal compounds," in Comprehensive Organometallic Chemistry III, eds D. Mingos, P. Micheal, and R. H. Crabtree (Elsevier Ltd.), 1-57. doi: 10.1016/B0-08-045047-4/ 00001-7

Pfletschinger, A., Dargel, T. K., Bats, J. W., Schmalz, H. G., and Koch, W. (1999). Structural and energetical characterization of reactive intermediates derived from toluene - $\mathrm{Cr}(\mathrm{CO})_{3}$. Chem. Eur. J. 5, 537-545. doi: 10.1002/(SICI)15213765(19990201)5:2\&lt;537::AID-CHEM537\&gt;3.0.CO;2-I

Porter, K. A., Schier, A., and Schmidbaur, H. (2003). Auration of thiophene and furan: structures of the 2-mono- and 2,2-diaurated products. Organometallics 22, 4922-4927. doi: 10.1021/om030575f

Preethalayam, P., Krishnan, K. S., Thulasi, S., Chand, S. S., Joseph, J., Nair, V., et al. (2017). Recent advances in the chemistry of pentafulvenes. Chem. Rev. 117, 3930-3989. doi: 10.1021/acs.chemrev.6b00210

Rafael, U., Laguua, A., Fernhdez, E. J., and Jones, P. G. (1988). (Polyhalophenyl)silver(I) complexes as arylating agents: crystal structure of $\left[\left(\mu-2,4,6-\mathrm{C}_{6} \mathrm{~F}_{3} \mathrm{H}_{2}\right)\left(\mathrm{AuPPh}_{3}\right)_{2}\right] \mathrm{ClO}_{4}$. J. Organomet. Chem. 350, 129-138. doi: 10.1016/0022-328X(88)80367-X

Rees, C. W., and von Angerer, E. (1972). Pyran-2-ylidene carbene complexes. J. Chem. Soc. Chem. Comm. 420. doi: 10.1039/c39720000420

Richards, J. H., and Hill, E. A. (1959). $\alpha$-metallocenyl carbonium ions. J. Am. Chem. Soc. 81, 3484-3485. doi: 10.1021/ja01522a089

Ritchie, C. D. (1986). Cation-anion combination reactions. 26. A review. Can. J. Chem. 64, 2239-2256. doi: 10.1139/v86-370

Roithová, J., Janková, Š., Jašíková, L., Váňa, J., and Hybelbauerová, S. (2012). Goldgold cooperation in the addition of methanol to alkynes. Angew. Chem. Int. Ed. 51, 8378-8382. doi: 10.1002/anie.201204003

Rybinskaya, M. I., Kreindlin, A. Z., Struchkov, Y. T., and Yanovsky, A. I. (1989). On the problem of the stabilization of $\alpha$-metallocenylcarbocation. Synthesis, properties and crystal structure of $\left[\mathrm{C}_{5} \mathrm{Me}_{5} \mathrm{OsC}_{5} \mathrm{Me}_{4} \mathrm{CH}_{2}^{+}\right] \mathrm{BPh}_{4}^{-} \cdot \mathrm{CH}_{2} \mathrm{Cl}_{2}$. J. Organomet. Chem. 359, 233-243. doi: 10.1016/0022-328X(89)85433-6

Schmidbaur, H. (1990). The fascinating implications of new results in gold chemistry. Gold Bull. 23, 11-21. doi: 10.1007/BF03214710

Schrock, R. R. (2001). Transition metal-carbon multiple bonds. J. Chem. Soc. Dalt. Trans. 2541-2550. doi: 10.1039/b104609h

Schrock, R. R. (2005). High oxidation state alkylidene and alkylidyne complexes. Chem. Commun. 2773-2777. doi: 10.1039/b504541j

Schumann, H., Glanz, M., Girgsdies, F., Hahn, F. E., Tamm, M., and Grzegorzewski, A. (1997). Cyclopropenylidene adducts of divalent germanium, tin, and lead. Angew. Chem. Int. Ed. 36, 2232-2234. doi: 10.1002/anie.199722321

Seidel, G., Lehmann, C. W., and Fürstner, A. (2010). Elementary steps in gold catalysis: the significance of gem-diauration. Angew. Chem. Int. Ed. 49, 8466-8470. doi: 10.1002/anie.201003349

Shahzad, S. A., Sajid, M. A., Khan, Z. A., and Canseco-Gonzalez, D. (2017). Gold catalysis in organic transformations: a review. Synth. Commun. 47, 735-755. doi: 10.1080/00397911.2017.1280508

Shen, J. K., Basolo, F., Tucker, D. S., and Hughes, R. P. (1993). Kinetics of CO substitution in reactions of $\eta^{3}$-cyclopropenyl complexes of iron, cobalt, rhodium, and iridium with phosphorus ligands. First examples of a dissociative mechanism for CO substitution in the cobalt triad carbonyl complexes. J. Am. Chem. Soc. 115, 11312-11318. doi: 10.1021/ja00077a033

Shriver, D. F. (1970). Transition metal basicity. Acc. Chem. Res. 3, 231-238. doi: 10.1021/ar50031a004 
Shrock, R. R. (2002). High oxidation state multiple metal-carbon bonds. Chem. Rev. 102, 145-179. doi: 10.1021/cr0103726

Sime, R. L., and Sime, R. J. (1974). The crystal structure of ferrocenyldiphenylcyclopropenium tetrafluoroborate, a stable carbonium ion salt. J. Am. Chem. Soc. 96, 892-896. doi: 10.1021/ja00810a039

Sørensen, T. J., Madsen, A. Ø., and Laursen, B. W. (2014). Synthesis and structures of $\mathrm{N}$-alkyl-1,13-dimethoxychromeno-[2,3,4-kl] acridinium salts: the missing azaoxa[4]helicenium. Chem. Eur. J. 20, 6391-6400. doi: 10.1002/chem.201400082

Stephen, A., Hashmi, K., Braun, I., Rudolph, M., and Rominger, F. (2012). The role of gold acetylides as a selectivity trigger and the importance of gem-diaurated species in the gold-catalyzed hydroarylating-aromatization of arene-diynes. Organometallics 31, 644-661. doi: 10.1021/om200946m

Tamm, M., Grzegorzewski, A., and Hahn, F. E. (1995). Pentacarbonylchromium( 0 ) and -tungsten ( 0 ) complexes with the bis( diisopropylamino) cyclopropenylidene ligand. J. Organomet. Chem. 501, 309-313. doi: 10.1016/0022-328X(95)05702-Q

Tantillo, D. J., Hietbrink, B. N., Merlic, C. A., and Houk, K. N. (2000). Attenuating and supplanting nonclassical stabilization: $\mathrm{Cr}(\mathrm{CO})_{3}-$ complexed benzonorbornenyl cations. J. Am. Chem. Soc. 122, 7136-7137. doi: $10.1021 / \mathrm{ja} 000621 \mathrm{~s}$

Trahanovsky, W. S., and Wells, D. K. (1969). Communications to the editor: arenemetal complexes. I. Thermodynamic stabilities of substituted benzyl cations complexed with tricarbonylchromium. J. Am. Chem. Soc. 91, 5870-5871. doi: 10.1021/ja01049a029

Tuggle, R. M., and Weaver, D. L. (1971a). The crystal structure and properties of $\pi$-triphenylcyclopropenylchlorodipyridinenickel(0)-pyridine, a $\pi$ complex of a three-membered aromatic ring. Inorg. Chem. 10, 2599-2603. doi: 10.1021/ic50105a046

Tuggle, R. M., and Weaver, D. L. (1971b). The crystal and molecular structure of the mixed sandwich complex $\pi$-cyclopentadienyl- $\pi$ triphenylcyclopropenylnickel, $\left(\pi-\mathrm{C}_{5} \mathrm{H}_{5}\right) \mathrm{Ni}\left(\pi-\mathrm{C}_{3}\left(\mathrm{C}_{6} \mathrm{H}_{5}\right)_{3}\right)$. Inorg. Chem. 10, 1504-1510. doi: 10.1021/ic50101a038
Weiss, R., and Priesner, C. (1978). Coordinatively unsaturated transition metalsubstituted cyclopropenylium systems. Angew. Chem. Int. Ed. 17, 457-458. doi: 10.1002/anie.197804571

Winemiller, M. D., Kopach, M. E., and Harman, W. D. (1997). Protonation of unactivated aromatic hydrocarbons on Osmium(II): stabilization of arenium cations via unprecedented $\eta^{2}$ - and $\eta^{3}$-coordination. J. Am. Chem. Soc. 119, 2096-2102. doi: 10.1021/ja963299n

Winstein, S., and Trifan, D. (1952). Neighboring carbon and hydrogen. XI. Solvolysis of exo-norbornyl p-bromobenzenesulfonate. J. Am. Chem. Soc. 74, 1154-1160. doi: 10.1021/ja01125a007

Yoshida, Z. (1982). Novel Pi systems possessing cyclopropenylidene moiety. Pure Appl. Chem. 54, 1059-1074. doi: 10.1351/pac198254051059

You, D., Yang, H., Sen, S., and Gabbaï, F. P. (2018). Modulating the $\sigma$-accepting properties of an antimony z-type ligand via anion abstraction: remotecontrolled reactivity of the coordinated platinum atom. J. Am. Chem. Soc. 140, 9644-9651. doi: 10.1021/jacs.8b05520

Zhdanko, A., and Maier, M. E. (2013). Quantitative evaluation of the stability of gem -diaurated species in reactions with nucleophiles. Organometallics 32, 2000-2006. doi: 10.1021/om400083f

$\mathrm{Zi}, \mathrm{W}$., and Toste, F. D. (2016). Recent advances in enantioselective gold catalysis. Chem. Soc. Rev. 45, 4567-4589. doi: 10.1039/C5CS00929D

Conflict of Interest Statement: The authors declare that the research was conducted in the absence of any commercial or financial relationships that could be construed as a potential conflict of interest.

Copyright ( $\odot 2019$ Goodman, Mei and Gianetti. This is an open-access article distributed under the terms of the Creative Commons Attribution License (CC BY). The use, distribution or reproduction in other forums is permitted, provided the original author(s) and the copyright owner(s) are credited and that the original publication in this journal is cited, in accordance with accepted academic practice. No use, distribution or reproduction is permitted which does not comply with these terms. 